\title{
Intercomparison of middle atmospheric meteorological analyses for the Northern Hemisphere winter 2009-2010
}

\author{
John P. McCormack ${ }^{1, a}$, V. Lynn Harvey ${ }^{2,3}$, Cora E. Randall ${ }^{2,3}$, Nicholas Pedatella ${ }^{4}$, Dai Koshin ${ }^{5,8}$, Kaoru Sato ${ }^{5}$, \\ Lawrence Coy $^{6,7}$, Shingo Watanabe ${ }^{8}$, Fabrizio Sassi ${ }^{1}$, and Laura A. Holt ${ }^{9}$ \\ ${ }^{1}$ Space Science Division, Naval Research Laboratory, Washington D.C., USA \\ ${ }^{2}$ Laboratory for Atmospheric and Space Physics, University of Colorado, Boulder CO, USA \\ ${ }^{3}$ Department of Atmospheric and Oceanic Sciences, University of Colorado, Boulder CO, USA \\ ${ }^{4}$ High Altitude Observatory, National Center for Atmospheric Research, Boulder CO, USA \\ ${ }^{5}$ Department of Earth and Planetary Science, The University of Tokyo, Tokyo, Japan \\ ${ }^{6}$ Science Systems and Applications, Lanham MD, USA \\ ${ }^{7}$ NASA Goddard Space Flight Center, Greenbelt MD, USA \\ ${ }^{8}$ Japan Agency for Marine-Earth Science and Technology, Yokohama, Japan \\ ${ }^{9}$ NorthWest Research Associates, Boulder CO, USA \\ ${ }^{a}$ now at: Heliophysics Division, Science Mission Directorate, NASA Headquarters, Washington D.C., USA
}

Correspondence: V. Lynn Harvey (lynn.harvey@lasp.colorado.edu)

Received: 13 March 2021 - Discussion started: 24 March 2021

Revised: 28 July 2021 - Accepted: 12 October 2021 - Published: 3 December 2021

\begin{abstract}
Detailed meteorological analyses based on observations extending through the middle atmosphere $(\sim 15$ to $100 \mathrm{~km}$ altitude) can provide key information to whole atmosphere modeling systems regarding the physical mechanisms linking day-to-day changes in ionospheric electron density to meteorological variability near the Earth's surface. However, the extent to which independent middle atmosphere analyses differ in their representation of wave-induced coupling to the ionosphere is unclear. To begin to address this issue, we present the first intercomparison among four such analyses, JAGUAR-DAS, MERRA-2, NAVGEM-HA, and WACCMX+DART, focusing on the Northern Hemisphere (NH) 2009-2010 winter, which includes a major sudden stratospheric warming (SSW). This intercomparison examines the altitude, latitude, and time dependences of zonal mean zonal winds and temperatures among these four analyses over the 1 December 2009 to 31 March 2010 period, as well as latitude and altitude dependences of monthly mean amplitudes of the diurnal and semidiurnal migrating solar tides, the eastward-propagating diurnal zonal wave number 3 nonmigrating tide, and traveling planetary waves associated with the quasi- $5 \mathrm{~d}$ and quasi- $2 \mathrm{~d}$ Rossby modes. Our results show generally good agreement among the four analy-
\end{abstract}

ses up to the stratopause ( $\sim 50 \mathrm{~km}$ altitude). Large discrepancies begin to emerge in the mesosphere and lower thermosphere owing to (1) differences in the types of satellite data assimilated by each system and (2) differences in the details of the global atmospheric models used by each analysis system. The results of this intercomparison provide initial estimates of uncertainty in analyses commonly used to constrain middle atmospheric meteorological variability in whole atmosphere model simulations.

\section{Introduction}

The atmospheric region from approximately 15 to $100 \mathrm{~km}$ altitude spanning the stratosphere, mesosphere, and lower thermosphere is often referred to as the "middle atmosphere". Through recent advances in numerical modeling and data assimilation capabilities, it is now understood that the middle atmosphere plays an important role in determining how meteorological variability near the Earth's surface affects the state of the coupled thermosphere-ionosphere (T-I) system ( $\sim 100$ to $500 \mathrm{~km}$ altitude) on timescales from hours to months. In addition to the well-established solar and geo- 


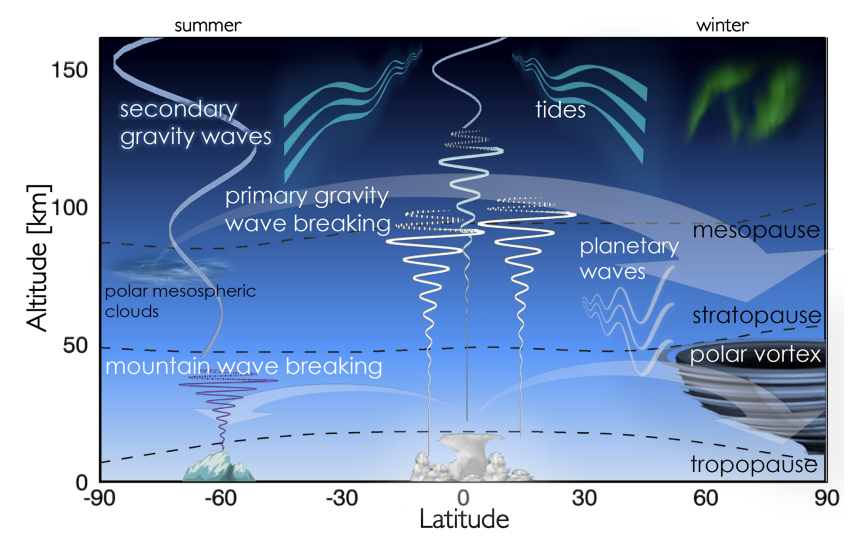

Figure 1. Sources of meteorological variability in the middle atmosphere impacting the thermosphere-ionosphere system.

magnetic drivers of the T-I system, this meteorological variability can impact the performance of space-based geolocation and global communication systems, and this impact is particularly noticeable during times of reduced solar activity. Specifically, these space-based systems are affected by rapid changes in the ionospheric electron content, which is determined by a complex interplay between variations in the thermospheric density, chemical composition, and circulation, particularly in the dynamo region of the thermosphere from 100 to $200 \mathrm{~km}$ that includes the ionospheric $\mathrm{E}$ and lower F regions.

Figure 1 illustrates examples of internal drivers of T-I variability, including planetary-scale waves, gravity (or buoyancy) waves, and tides that are produced in the troposphere and stratosphere and propagate upward through the middle atmosphere. The present study focuses on how some basic characteristics of these drivers are represented in meteorological analyses that extend throughout the middle atmosphere as this critical altitude region can be viewed as the conduit between meteorological variability near the surface and related changes in the T-I system. Coupling between the state of the middle atmosphere and the behavior of the T-I system has been demonstrated in observational studies (e.g., Goncharenko and Zhang, 2008; Chau et al., 2009; Goncharenko et al., 2010; Pedatella and Forbes, 2010) linking variations in total electron content and ion drift with the reversal of polar stratospheric flow in the Northern Hemisphere $(\mathrm{NH})$ winter during sudden stratospheric warmings (SSWs). Subsequent modeling studies showed that changes in the amplitude and phase of both migrating and nonmigrating tides are the primary drivers of changes in the T-I state in response to SSWs that result in anomalous ionospheric behavior. However, as shown by, for example, Pedatella et al. (2014a), whole atmosphere models produce widely varying estimates of the tidal variability within the T-I region. The reason for this disagreement can be attributed to both differences in model physics and differences in the data sets used to constrain these models.

Differences in model physics, especially the treatment of gravity wave processes, no doubt play a role in explaining some of the inter-model discrepancies reported by Pedatella et al. (2014a) with respect to both the background zonal mean state and tidal variability within the thermosphere. The primary gravity waves illustrated in Fig. 1 are excited near the surface and propagate up, growing in amplitude and becoming unstable or "breaking" in the mesosphere, depositing heat and momentum into the background flow. Primary gravity wave breaking often occurs at spatial scales too small to be resolved in global models, and typically it is represented in these models by single column parameterizations with tropospheric sources. Also shown in Fig. 1 are secondary gravity waves triggered by flow instabilities related to primary gravity wave breaking in the mesosphere, which may propagate into the lower thermosphere and drive T-I variability (Becker and Vadas, 2018; Vadas and Becker, 2018). Currently, global atmospheric models extending into the thermosphere do not account for the effects of secondary gravity wave breaking. More advanced treatments of gravity wave breaking in the mesosphere and lower thermosphere (MLT) region are thus needed to better understand and ultimately predict internal drivers of T-I variability.

Pedatella et al. (2014a) also noted that some of the models employed different meteorological analyses to constrain (or "nudge") meteorological variability in the middle atmosphere. These analyses are produced through the assimilation of atmospheric observations mainly in the troposphere and stratosphere and were initially developed for a wide range of applications that include initialization and validation of numerical weather prediction (NWP) systems and longterm climate studies. Some well-known examples of these analyses include the second-generation Modern-Era Retrospective analysis for Research and Applications (MERRA-2; Bosilovich et al., 2015), the European Centre for Mediumrange Weather Forecasting Interim Atmospheric Reanalysis (ERA-I; Dee et al., 2011), the National Centers for Environmental Prediction/National Center for Atmospheric Research (NCEP/NCAR) reanalysis (Kalnay et al., 1996; Kistler et al., 2001), and the Japanese Meteorological Agency's 55-year reanalysis (JRA55; Kobayashi et al., 2015). Understanding how whole atmospheric model simulations of T-I variability are impacted by the use of different meteorological reanalyses as constraints (e.g., Sassi et al., 2021) could help understand the origins of inter-model discrepancies such as those noted by Pedatella et al. (2014a).

A recent intercomparison of several reanalyses was performed as part of the Stratospheric Reanalysis Intercomparison Project (S-RIP; Fujiwara et al., 2017), with a chapter focusing specifically on the ability of reanalyses to capture key processes in the upper stratosphere and lower mesosphere (Harvey et al., 2021). A key finding of Harvey et al. (2021) is that the most commonly used reanalyses (e.g., MERRA-2, 
ERA-I, JRA55) show good agreement in their representation of the zonal mean atmospheric state and in their representation of planetary waves (PWs) and tides up to $\sim 50 \mathrm{~km}$ altitude, but the representations diverge quite substantially above $50 \mathrm{~km}$ altitude, particularly in the equatorial region. This is not surprising since these systems were originally developed with a focus on tropospheric and stratospheric applications, with top levels extending into the lower mesosphere ( $\sim 60 \mathrm{~km}$ altitude) in most cases. In addition, the lack of wind measurements at low latitudes above $10 \mathrm{hPa}(\sim 30 \mathrm{~km})$ combined with the breakdown of midlatitude geostrophic balance adds to the analysis uncertainty in this important tidal region. However, this disagreement among reanalyses above the stratopause poses a challenge for emerging whole atmosphere modeling applications, such as those described above, that seek to quantify the response of the T-I system to meteorological variability in the middle atmosphere. For example, Sassi et al. (2018) demonstrated that whole atmosphere model simulations constrained with high-altitude meteorological analyses extending up to $\sim 90 \mathrm{~km}$ altitude represented day-to-day variability in the lower thermosphere more realistically than simulations constrained with analyses that only extended up to $\sim 60 \mathrm{~km}$ altitude, especially around the time of a major SSW. Constraining whole atmosphere models by using meteorological analyses with widely varying representations of the middle atmosphere state above $\sim 60 \mathrm{~km}$ altitude makes it difficult to conclusively identify and predict the physical drivers that are responsible for linking lower atmospheric meteorology to ionospheric variability.

To address the emerging need for accurate global atmospheric analyses throughout the entire middle atmosphere, high-altitude data assimilation and modeling systems (e.g., Pedatella et al., 2014b; McCormack et al., 2017; Koshin et al., 2020) have been developed recently to provide observation-based constraints of middle atmospheric meteorological variability for whole atmosphere models (Sassi et al., 2018; McDonald et al., 2018; Pedatella et al., 2019). These systems produce global meteorological analyses by incorporating both standard operational meteorological observations near the surface and satellite-based observations of the middle atmosphere from dedicated NASA research missions such as Aura (Schoeberl et al., 2006) and TIMED (Thermosphere-Ionosphere-Mesosphere Energetics and Dynamics; Yee et al., 1999). Typical top levels for these new systems extend to $90 \mathrm{~km}$ altitude or higher, so each of these systems provides valuable resources for studying the dynamics of and variability in the middle atmosphere. Examining the level of agreement among these new high-altitude systems is a first step towards understanding how whole atmosphere model simulations may be affected when constrained by different sets of meteorological input.

This paper presents the first intercomparison of four analyses extending into the middle atmosphere: the highaltitude version of the Navy Global Environmental Model (NAVGEM-HA; Eckermann et al., 2018), the Whole At- mosphere Community Climate Model with thermosphereionosphere eXtension using the Data Assimilation Research Testbed (WACCMX+DART; Pedatella et al., 2018), the Japanese Atmospheric General circulation model for Upper Atmosphere Research with Data Assimilation System (JAGUAR-DAS; Koshin et al., 2020; 2021), and MERRA2. Each of these systems assimilates middle atmosphere data to varying degrees, with top output levels ranging from 80 to $\sim 500 \mathrm{~km}$ altitude. The objective of this study is to quantify the similarities and differences between these four analyses. The results are useful for the assessment of uncertainty in constrained or "nudged" whole atmosphere simulations arising from differences in meteorological inputs. These results can also be used to highlight where further improvements in middle atmospheric data assimilation and modeling are needed in order to improve our understanding of how meteorological variability impacts day-to-day variability in ionospheric conditions, especially during quiet Sun conditions.

The initial plan for this intercomparison was conceived as a follow-on study of Harvey et al. (2021) by the SPARC (Stratosphere-troposphere Processes and their Role in Climate) Data Assimilation Working Group (https:// www.sparc-climate.org/activities/data-assimilation/, last access: 16 November 2021) to examine high-altitude meteorological analyses extending throughout the middle atmosphere. Due to the large computational resources needed to generate these types of meteorological analyses, a detailed multi-year intercomparison is not currently within the scope of the present study. Instead, we focus on a detailed examination of the four analyses over the 1 December 2009 to 31 March 2010 period, which includes a major SSW. This work is particularly interested in mesospheric wind and temperature disturbances that occur in late January (Goncharenko et al., 2013; Jones et al., 2018; McCormack et al., 2017), 2 weeks before the onset of easterlies in the stratosphere on 9 February (Butler et al., 2017). This Northern Hemisphere $(\mathrm{NH})$ wintertime period is useful since it provides a prime example of a dramatic shift in middle atmospheric circulation that has been studied extensively through both observations and modeling studies.

The paper is organized as follows. The four meteorological analyses used in this intercomparison (NAVGEM-HA, WACCMX+DART, JAGUAR-DAS, and MERRA-2) are described in Sect. 2. Section 3 describes the numerical methods used to analyze space-time variations in the data related to specific PW and tidal features. Section 4 presents an intercomparison of the zonal mean zonal wind and zonal mean temperature data, while Sect. 5 presents an intercomparison of the PW and tidal signatures. The results of this study are summarized, and implications for future research are discussed, in Sect. 6. 


\section{Data and methods}

This section provides an overview of each of the four highaltitude meteorological systems used in the present intercomparison of the $\mathrm{NH}$ winter period extending from 1 December 2009 to 31 March 2010. Each of these systems combines a data assimilation (DA) component with an atmospheric model component that together produce global synoptic analyses of key atmospheric quantities. In the discussion below, we describe the main features of the DA and modeling systems relevant for capturing specific PW and tidal components; previous observational and modeling studies (see Sect. 1) have shown these PWs and tides can impact day-today variability in the $\mathrm{T}-\mathrm{I}$ system. These include the migrating diurnal and semidiurnal solar tides (referred to here as DW1 and SW2, respectively), the nonmigrating diurnal eastward zonal wave number 3 tidal component (DE3), the quasi-2 $\mathrm{d}$ wave (Q2DW), and the quasi-5 d wave (Q5DW).

For this intercomparison, we examine global gridded data sets of temperature, zonal wind, and geopotential height from four different systems extending throughout the middle atmosphere and in some cases (JAGUAR-DAS and WACCMX+DART) into the thermosphere. The main sources of middle atmosphere observations for these systems are retrieved vertical temperature profiles from the Aura Microwave Limb Sounder (MLS; Schwartz et al., 2008) between $\sim 16$ and $90 \mathrm{~km}$ altitude and extending from $82^{\circ} \mathrm{S}$ to $82^{\circ} \mathrm{N}$ latitude, as well as from the TIMED Sounding of the Atmosphere using Broadband Emission of Radiation (SABER; Remsberg et al., 2008) instrument between $\sim 16$ and $105 \mathrm{~km}$ altitude with latitude coverage that alternated between its south-viewing mode $\left(83^{\circ} \mathrm{S}-52^{\circ} \mathrm{N}\right)$ and northviewing mode $\left(83^{\circ} \mathrm{N}-52^{\circ} \mathrm{S}\right)$ on 11 January 2010 . Further details on each high-altitude analysis system can be found in the discussion below and references therein. All data used in this study are publicly available as described in the "Data availability" section.

Table 1 gives overall references for each system, lists the horizontal, vertical, and temporal resolutions, gives the vertical range for the systems, and provides references for the orographic and non-orographic gravity wave parameterizations implemented in each system.

\subsection{NAVGEM-HA}

NAVGEM-HA is a research version of the US Navy's operational NWP system developed for middle atmosphere applications. It processes over 6 million atmospheric observations within its standard $6 \mathrm{~h}$ assimilation window, consisting of surface station reports, radiosondes, and numerous operational meteorological satellites (McCormack et al., 2017; Eckermann et al., 2018). In addition to MLS and SABER temperature retrievals, NAVGEM-HA also assimilates vertical profiles of ozone and water vapor from MLS, as well as microwave radiances from the upper atmospheric sounder (UAS) channels of the Special Sensor Microwave Imager/Sounder (SSMI/S), as illustrated in Fig. 3a of Eckermann et al. (2018). Over the 2009-2010 period of this intercomparison, three different space-based platforms (designated F16, F17, and F18) from the Defense Meteorological Satellite Program (DMSP) provided SSMI/S UAS observations, together offering a unique source of operational temperature information in the upper stratosphere and lower mesosphere with excellent global coverage (Hoppel et al., 2013; McCormack et al., 2017). At present, only a single DMSP platform (F17) provides SSMI/S UAS observations, and there are no plans to extend the UAS capability to any future missions.

NAVGEM-HA produces atmospheric data sets of winds, temperature, geopotential height, ozone, and water vapor by combining a hybrid four-dimensional variational (or 4DVAR) DA solver with a global spectral atmospheric forecast model. The hybrid 4DVAR approach uses a linear combination of static (i.e., constant in time) model error covariance estimates and model error covariances estimated from 80-member ensembles of $6 \mathrm{~h}$ forecasts that vary over time (Kuhl et al., 2013). The present study uses a linear weighting factor of 0.5 , meaning the static and time-dependent model error covariances are equally weighted. Further details of the DA solver, including the incorporation of middle atmosphere observation error and methods of bias correction between middle atmosphere satellite data sets, are provided in Kuhl et al. (2013) and Eckermann et al. (2018).

This intercomparison examines NAVGEM-HA zonal wind, temperature, and geopotential height fields produced with the T119L74 version of the system, where T119 refers to the triangular wave number truncation of the spectral forecast model and corresponds to a horizontal grid spacing of $1^{\circ}$ in latitude and longitude, and L74 refers to 74 vertical model levels extending from the surface to the top pressure of $6 \times 10^{-5} \mathrm{hPa}$. The NAVGEM-HA vertical coordinate is hybrid $\sigma$-p that is terrain following near the surface and transitions to isobaric above the $88 \mathrm{hPa}$ level (approximately $17 \mathrm{~km}$ altitude). The spacing of the model's vertical levels is $\sim 2 \mathrm{~km}$ in the stratosphere, $\sim 3 \mathrm{~km}$ in the mesosphere, and $>4 \mathrm{~km}$ in the lower thermosphere. Strong horizontal diffusion is applied to the top two model levels (above $\sim 100 \mathrm{~km}$ altitude) in order to prevent numerical instabilities resulting from, e.g., spurious wave reflection. The resulting analyses near the model top are heavily influenced by this imposed diffusion. Therefore, in this study we limit our focus to altitudes below $95 \mathrm{~km}$ geometric altitude, where previous validation studies (e.g., McCormack et al., 2017; Dhadly et al., 2018; Stober et al., 2020) have shown NAVGEM-HA to produce reliable results. The NAVGEM-HA system produces analyses every $6 \mathrm{~h}$, and these fields are supplemented by 3-hourly forecast fields produced by the system as part of the 4DVAR framework, providing an effective 3-hourly sampling rate for the extraction of tidal signatures in the horizontal wind and temperature fields. 
Table 1. List of analysis datasets used in this paper, overall references describing each system, the horizontal, vertical, and temporal characteristics of the analysis output, the model top, and references for gravity wave specifications. In the fifth column, ORO refers to the parametrization for orographic gravity waves, while NON refers to that of non-orographic gravity waves.

\begin{tabular}{|c|c|c|c|c|}
\hline Analysis system & Reference(s) & $\begin{array}{l}\text { Horizontal grid, } \\
\text { vertical grid, and } \\
\text { output frequency }\end{array}$ & Vertical range & $\begin{array}{l}\text { Reference(s) for } \\
\text { gravity wave drag } \\
\text { parameterizations }\end{array}$ \\
\hline JAGUAR-DAS & Koshin et al. $(2020,2021)$ & $\begin{array}{l}2.8125^{\circ} \text { lat and long, } \\
\Delta \mathrm{z} \approx 1 \mathrm{~km} \\
\Delta \mathrm{t}=6 \mathrm{~h}\end{array}$ & $\begin{array}{l}\text { Surface to } 1 \times 10^{-6} \mathrm{hPa} \\
(\sim 150 \mathrm{~km})\end{array}$ & $\begin{array}{l}\text { ORO: McFarlane (1987) } \\
\text { NON: Hines (1997); } \\
\text { Watanabe (2008) }\end{array}$ \\
\hline MERRA-2 & $\begin{array}{l}\text { Bosilovich et al. (2015); } \\
\text { Gelaro et al. (2017); } \\
\text { Molod et al. (2015) }\end{array}$ & $\begin{array}{l}0.5^{\circ} \text { lat by } 0.625^{\circ} \text { long, } \\
\Delta \mathrm{z} \approx 2-5 \mathrm{~km} \\
\Delta \mathrm{t}=3 \mathrm{~h}\end{array}$ & $\begin{array}{l}\text { Surface to } \\
0.01 \mathrm{hPa} \\
(\sim 75 \mathrm{~km})\end{array}$ & $\begin{array}{l}\text { ORO: McFarlane (1987) } \\
\text { NON: Garcia and Boville (1994); } \\
\text { Molod et al. (2015) }\end{array}$ \\
\hline NAVGEM-HA & $\begin{array}{l}\text { McCormack et al. (2017); } \\
\text { Eckermann et al. (2018) }\end{array}$ & $\begin{array}{l}1^{\circ} \text { lat and long, } \\
\Delta \mathrm{z} \approx 2-4 \mathrm{~km} \\
\Delta \mathrm{t}=3 \mathrm{~h}\end{array}$ & $\begin{array}{l}\text { Surface to } \\
6 \times 10^{-5} \mathrm{hPa} \\
(\sim 120 \mathrm{~km})\end{array}$ & $\begin{array}{l}\text { ORO: Webster et al. (2003) } \\
\text { NON: Eckermann (2011) }\end{array}$ \\
\hline WACCMX+DART & $\begin{array}{l}\text { Liu et al. (2018); Pedatella et al. } \\
\text { (2018) }\end{array}$ & $\begin{array}{l}1.9^{\circ} \text { lat by } 2.5^{\circ} \text { long, } \\
\Delta \mathrm{z} \approx 1-5 \mathrm{~km} \\
\Delta \mathrm{t}=1 \mathrm{~h}\end{array}$ & $\begin{array}{l}\text { Surface to } \\
4.1 \times 10^{-10} \mathrm{hPa} \\
(\sim 500-700 \mathrm{~km})\end{array}$ & $\begin{array}{l}\text { ORO: McFarlane (1987) } \\
\text { NON: Beres et al. (2005); Richter } \\
\text { et al. (2010); Garcia et al. (2017) }\end{array}$ \\
\hline
\end{tabular}

\subsection{MERRA-2}

MERRA-2 temperature, geopotential height, and zonal winds are used in this study (Gelaro et al., 2017). The 3-hourly fields on the native model grid ("3d_asm_Nv"; GMAO, 2015) provide the best time resolution available, with horizontal grid spacing of $0.625^{\circ}$ longitude by $0.5^{\circ}$ latitude on 72 vertical levels that extend from the Earth's surface to $0.01 \mathrm{hPa}(\sim 75 \mathrm{~km})$. The vertical grid spacing is $\sim 2 \mathrm{~km}$ in the upper stratosphere and lower mesosphere, increasing to $\sim 5 \mathrm{~km}$ near $80 \mathrm{~km}$ altitude (see, e.g., Fujiwara et al., 2017). MERRA-2 assimilates a full range of ground-based and satellite radiance observations, including the stratospheric channels of the available Advanced Microwave Sounding Unit (AMSU-A) instruments (McCarty et al., 2016). During the time period of interest here MERRA-2 assimilates Aura MLS temperatures from 5 to $0.02 \mathrm{hPa}$ and ozone from 250 to $0.1 \mathrm{hPa}$ to better constrain the dynamics in the upper stratosphere and mesosphere (Gelaro et al., 2017). The MERRA-2 model component contains a stratospheric quasi-biennial oscillation (QBO; Molod et al., 2015), and the MERRA-2 analysis QBO winds match well with the available radiosonde observations (Coy et al. 2016; Kawatani et al. 2016). While MERRA-2 has an equatorial semi-annual oscillation (SAO), Kawatani et al. (2020) have shown that reanalyses can differ in their representation of the SAO near the stratopause.

\subsection{JAGUAR-DAS}

JAGUAR is a comprehensive numerical model that extends from the Earth's surface to the lower thermosphere $(\sim 150 \mathrm{~km})$. It is cooperatively developed by the Japan Agency for Marine-Earth Science and Technology (JAMSTEC), the Kyushu University, and the University of Tokyo based on the Model for Interdisciplinary Research on Cli- mate (MIROC) and the Kyushu-GCM (general circulation model; Watanabe and Miyahara, 2009). A full set of physical parameterizations necessary to simulate altitudes from the surface to $\sim 150 \mathrm{~km}$ is included, as described in Koshin et al. (2020). The JAGUAR model generates short-term forecasts that are used as background fields for the data assimilation system (JAGUAR-DAS), which employs a four-dimensional local ensemble transform Kalman filter (4D-LETKF) developed by Miyoshi and Yamane (2007). The forecast model has 124 vertical layers from the surface to $\sim 150 \mathrm{~km}$ and a T42 horizontal resolution. The vertical grid spacing is $1 \mathrm{~km}$ in the $50-100 \mathrm{~km}$ altitude range. As the uppermost layers are taken as a sponge layer, only data below $\sim 105 \mathrm{~km}$ altitude are usable for dynamical analysis. Following Koshin et al. (2020), the JAGUAR-DAS output used in the present study assimilates the standard National Centers for Environmental Prediction (NCEP) PREPBUFR dataset for the troposphere and lower stratosphere. For the stratosphere, mesosphere, and lower thermosphere, JAGUAR-DAS assimilates bias-corrected MLS temperature retrievals from 100 to $0.002 \mathrm{hPa}$ ( $\sim 16$ to $90 \mathrm{~km}$ altitude). The JAGUAR-DAS output used in the present study also includes three recent improvements: (1) introduction of incremental analysis update filtering to suppress generation of spurious waves, (2) a modified treatment of horizontal diffusion in the JAGUAR forecast model, and (3) assimilation of SABER temperature retrievals from 40 to $0.00014 \mathrm{hPa}(\sim 22$ to $110 \mathrm{~km}$ altitude) and the SSMI/S UAS microwave radiance measurements, described in Sect. 2.1, from 10 to $0.01 \mathrm{hPa}$ ( $\sim 30$ to $80 \mathrm{~km}$ ). These improvements will be described in an upcoming study by Koshin et al. (2021). Model error covariances were estimated from 50-member ensembles. The output from JAGUAR-DAS is 6-hourly and has horizontal grid spacing of $2.8125^{\circ}$ in latitude and longitude. 


\subsection{WACCMX+DART}

The background model in WACCMX+DART is WACCMX version 2.0 (Liu et al., 2018). WACCMX is an atmospheric component of the Community Earth System Model (CESM; Danabasoglu et al., 2020), and it encompasses the whole atmosphere from the surface to the upper thermosphere $\left(4.1 \times 10^{-10} \mathrm{hPa}, \sim 500\right.$ to $700 \mathrm{~km}$ depending on solar activity conditions). WACCMX incorporates the chemical, dynamical, and physical processes from WACCM version 4 (Marsh et al., 2013) and the Community Atmosphere Model version 4 (Neale et al., 2013) in the lower-middle atmosphere. Additional T-I processes are incorporated in WACCMX, including major species diffusion, ionosphere transport of $\mathrm{O}^{+}$, and self-consistent electrodynamics. The horizontal resolution of WACCMX is $1.9^{\circ}$ in latitude and $2.5^{\circ}$ in longitude. The vertical resolution ranges from $\sim 1 \mathrm{~km}$ in the lower stratosphere to $\sim 3 \mathrm{~km}$ in the upper mesosphere and is $\sim 4-5 \mathrm{~km}$ at higher altitudes. A detailed description of WACCMX version 2.0 can be found in Liu et al. (2018).

The data assimilation capability is implemented in WACCMX using the Data Assimilation Research Testbed (DART; Anderson et al., 2009) ensemble adjustment Kalman filter (Pedatella et al., 2014b, 2018). WACCMX+DART assimilates conventional meteorological observations (e.g., aircraft and radiosonde temperature and winds) and GPS radio occultation refractivity in the troposphere-stratosphere, as well as Aura MLS and TIMED SABER temperature observations up to $\sim 100 \mathrm{~km}$ altitude. To prevent spurious correlations, the observations are localized using a Gaspari-Cohn (Gaspari and Cohn, 1999) function with a half-width of 0.2 radians in the horizontal and 0.15 in $\ln \left(p_{0} / p\right)$ in the vertical, where $p$ is pressure and $p_{\mathrm{o}}$ is surface pressure. For the present study, WACCMX+DART simulations were performed using 40 ensemble members and a $6 \mathrm{~h}$ data assimilation cycle. Second-order divergence damping was applied in order to stabilize the model, as well as prevent large decreases in the $\mathrm{O} / \mathrm{N}_{2}$ ratio and electron density in the thermosphere and ionosphere (Pedatella et al., 2018). The secondorder divergence damping results in tidal amplitudes that are $50 \%-100 \%$ too small. Pedatella et al. (2020) demonstrated that the tidal amplitudes can be improved by using hourly data assimilation cycling; however, the present study makes use of existing simulations that utilized a $6 \mathrm{~h}$ data assimilation cycle. The WACCMX+DART 6-hourly analysis fields of zonal wind, temperature, and geopotential height are combined with short-term $(1-5 \mathrm{~h})$ forecasts, yielding hourly output for analysis in the present study.

\subsection{Space-time analysis}

To quantify the various PW and tidal components in the high-altitude analyses, we employ the two-dimensional fast Fourier transform (2DFFT) method introduced by Hayashi (1971). Following McCormack et al. (2009), daily zonal means are subtracted from each hourly (WACCMX+DART), 3-hourly (MERRA-2 and NAVGEM-HA), or 6-hourly (JAGUAR-DAS) longitude-time field for a given month, and then a cosine taper is applied to the first and last $10 \%$ of each record in time. The resulting power spectra describe the variance related to both eastward- and westward-propagating features as a function of frequency and zonal wave number. Individual components related to DW1, SW2, DE3, Q2DW, and Q5DW are isolated through the application of band-pass filters to the inverse 2DFFT (e.g., McCormack et al., 2009). The pass bands (described below) are determined by examining individual wave-number-frequency spectra in middle atmosphere temperature anomalies from all four analyses over the December-February (DJF) 2009-2010 period (not shown).

We also apply a continuous wavelet transform based on the S-transform method (Stockwell et al., 1996) to characterize the time variation of both migrating (DW1, SW2) and nonmigrating (DE3) tidal components throughout the 2009-2010 winter. The S-transform has been used previously to examine the time behavior of the SW2 component in NAVGEM-HA wind fields during the 2009-2010 and 2012-2013 NH winters (McCormack et al., 2017), and we now extend this type of analysis to examine time variations related to DW1, SW2, and DE3 in the upper mesosphere from the NAVGEM-HA, JAGUAR-DAS, and WACCMX+DART data sets. Following the method described in McCormack et al. (2017), the $\mathrm{S}$-transform produces estimates of wave amplitude as a function of both time and frequency. To evaluate the different tidal components with the S-transform, a one-dimensional FFT is first used to filter each data set to isolate the zonal wave number 1, 2, or 3 components, following Sassi et al. (2016). The S-transform is then applied to the horizontal wave-number-filtered time series of temperature anomalies (time mean removed), and the resulting wave amplitudes at frequencies of 1 and $2 \mathrm{cpd}$ (cycles per day) are examined. Significance levels for these results are estimated following Torrance and Compo (1998), in which we make use of the fact that the time mean of the S-transform returns the exact Fourier spectrum. The time means of the S-transform results produce spectra that are evaluated against a spectrum of a first-order autoregressive time series with the same variance as the input temperature time series, as described in Sassi et al. (2012). The $90 \%$ and $95 \%$ confidence values are constructed based on Eq. (18) in Torrance and Compo (1998).

For this initial intercomparison, we examine all available output from these meteorological analyses over the altitude region from 20 to $120 \mathrm{~km}$, with particular emphasis on the MLT region between $\sim 50$ and $90 \mathrm{~km}$ altitude. Unless other- 


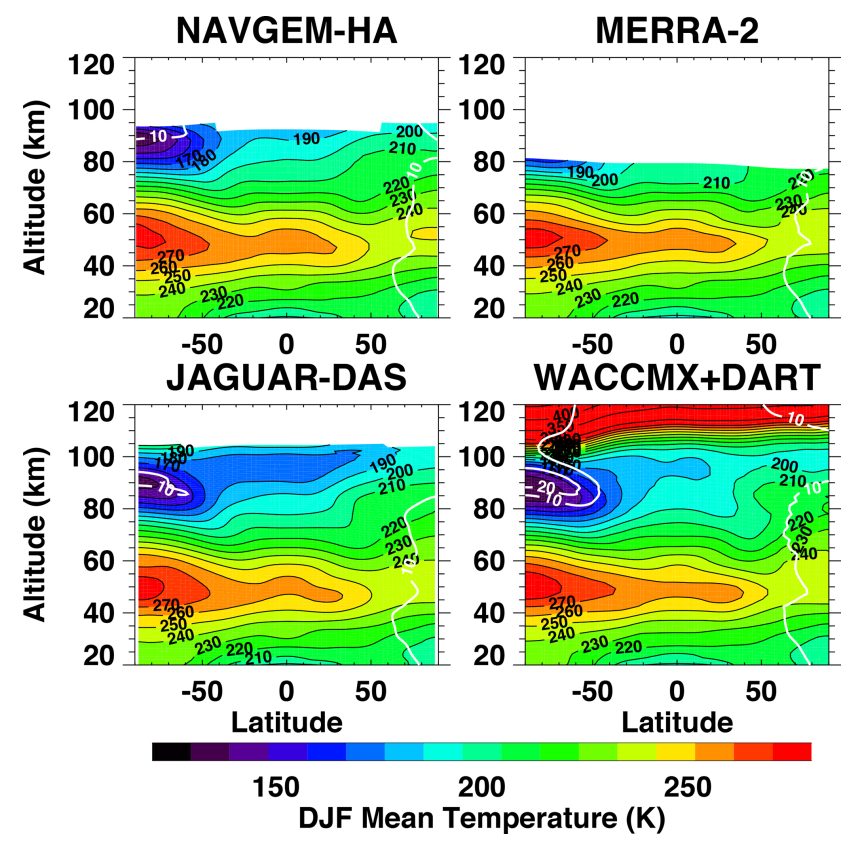

Figure 2. Latitude-altitude cross-sections of DJF 2009-2010 average zonal mean temperature in NAVGEM-HA, MERRA-2, JAGUAR-DAS, and WACCMX+DART. Thick white contours are temperature standard deviation values of 10 and $20 \mathrm{~K}$.

wise noted, all results are based on geometric altitude $Z$ computed using gridded geopotential height $H$ output by each system corrected for both altitude and latitude variations in gravitational acceleration following Lewis (2007):

$Z=\frac{R_{\mathrm{e}}(\phi) H}{\left(\frac{\gamma_{(\phi)}}{\gamma_{45}}\right) R_{\mathrm{e}}(\phi)-H}$,

where $H$ is the geopotential height in meters, $\phi$ is latitude in degrees, $\gamma_{45}$ is the surface gravitational acceleration at $45^{\circ}$ latitude $\left(9.80665 \mathrm{~m} \mathrm{~s}^{-2}\right), R_{\mathrm{e}}(\phi)$ is a latitude-dependent value of Earth's radius that corrects for the combined effect of gravitational and centrifugal forces, and the latitude-dependent gravitational acceleration $\gamma(\phi)$ on the surface of an ellipsoid of revolution is given by the expression

$\gamma(\phi)=\gamma_{\mathrm{e}}\left\{\frac{1+k_{\mathrm{s}} \sin ^{2}(\phi)}{\sqrt{1-e^{2} \sin ^{2}(\phi)}}\right\}$

using Somagliana's constant $k_{\mathrm{s}}=1.931853 \times 10^{-3}$, the Earth's eccentricity factor $e=0.081819$, and the gravitational acceleration at the Equator $\gamma_{\mathrm{e}}=9.7803253359 \mathrm{~m} \mathrm{~s}^{-2}$.

\section{Zonal mean results}

To begin, we examine how each of the four high-altitude meteorological analyses represent the latitude and altitude dependencies of zonal mean temperature and zonal mean zonal

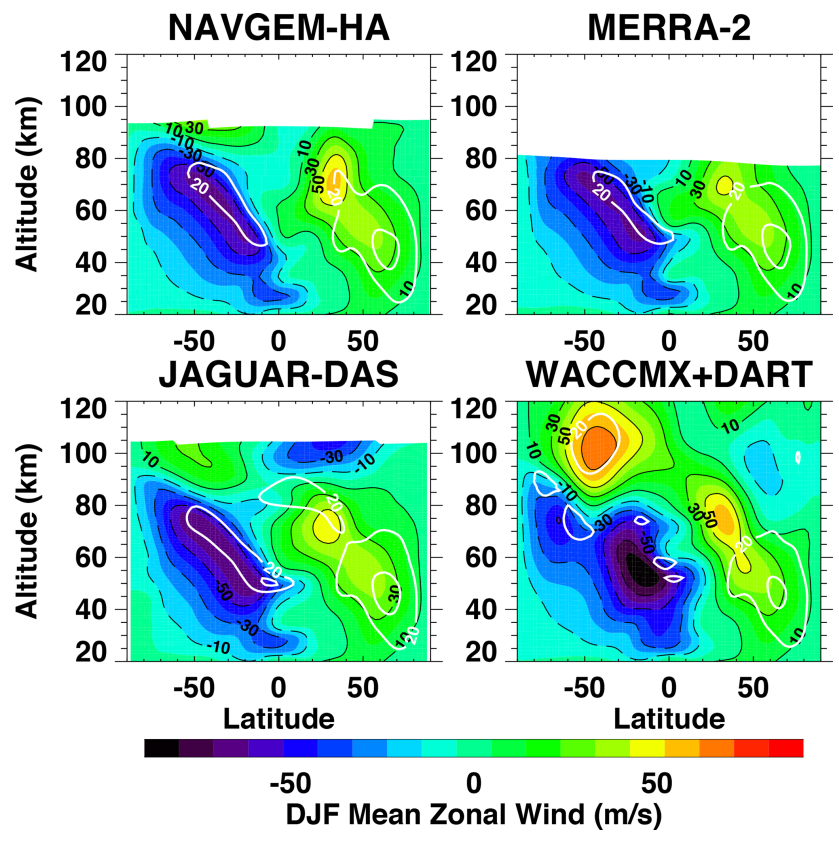

Figure 3. As in Fig. 2 but for zonal wind. Dashed black contours depict easterly winds. Thick white contours are zonal wind standard deviation values of 20 and $30 \mathrm{~m} \mathrm{~s}^{-1}$.

wind averaged over the DJF period 2009-2010. The zonal mean temperature distribution from 20 to $120 \mathrm{~km}$ altitude plotted in Fig. 2 reflects a balance between net radiative heating (driven primarily by stratospheric $\mathrm{O}_{3}$ heating and mesospheric $\mathrm{CO}_{2}$ cooling) and dynamically induced heating resulting from a thermally indirect (or residual) meridional circulation. This circulation is mainly produced by the cumulative effects of breaking PWs in the stratosphere and breaking gravity waves in the mesosphere. Similarly, the zonal mean zonal wind distributions plotted in Fig. 3 from all four analysis systems also reflect this balance between radiative and dynamical drivers of the middle atmospheric circulation. Consequently, the zonal mean temperature and zonal wind distributions produced by each analysis system can depend not only on the number and quality of middle atmospheric observations being directly assimilated but also on the physical parameterizations employed by the atmospheric model components to represent key processes (e.g., radiative heating and cooling, parameterization of sub-grid-scale gravity wave drag). By characterizing similarities and differences in the zonal mean state among the four systems, we can begin to understand the relative roles that observations and model physics may play in producing these high-altitude meteorological data sets.

Between 20 and $50 \mathrm{~km}$ altitude, the zonal mean temperature distributions among all four data sets are broadly similar, exhibiting temperatures below $210 \mathrm{~K}$ in the equatorial lower stratosphere near $20 \mathrm{~km}$ altitude, consistent with adiabatic cooling in the upward branch of the Brewer-Dobson 
circulation, as well as in the $\mathrm{NH}$ winter polar night region below $\sim 30 \mathrm{~km}$ altitude. Each system produces temperature maxima of $\sim 280 \mathrm{~K}$ near $50 \mathrm{~km}$ altitude at the South Pole related to peak ozone heating via absorption of solar UV radiation. The latitude structure of the stratopause varies somewhat among the different analyses, with JAGUAR-DAS exhibiting a local temperature maximum near $55 \mathrm{~km}$ altitude at the Equator, while WACCMX+DART exhibits little to no latitude variation in the altitude of the tropical temperature maximum. Near $80 \mathrm{~km}$ altitude, all four analyses are qualitatively similar, showing lower temperatures over the summer polar region arising from upward vertical motion and higher temperatures over the winter polar region related to downward vertical motion. The upward and downward vertical motions over the poles in the mesosphere are both features associated with a global residual meridional circulation from the summer to winter hemisphere driven by the effects of gravity wave drag; this circulation is represented by the broad arrow in Fig. 1. However, there are important quantitative differences among the DJF zonal mean temperature distributions, most notably in the tropics from 80 to $100 \mathrm{~km}$ altitude, where WACCMX+DART produces temperatures that are $>20 \mathrm{~K}$ warmer than corresponding temperatures produced by the NAVGEM-HA and JAGUAR-DAS systems. A warm bias at the tropical mesopause has been documented previously in free-running WACCM model simulations (e.g., Smith, 2012; Marsh et al., 2013; Harvey et al., 2019), but the cause is not yet fully understood. We also note that the summer polar temperature at $80 \mathrm{~km}$ altitude is $\sim 20 \mathrm{~K}$ colder in WACCMX+DART compared to the other three data sets.

Also plotted in Fig. 2 as heavy white contours are the corresponding temporal standard deviations of the zonal mean temperature during DJF from each analysis (see also Fig. S1 in the Supplement). All four analyses exhibit standard deviations exceeding $10 \mathrm{~K}$ at high northern latitudes, reflecting the relatively large amount of dynamical variability in the $\mathrm{NH}$ winter polar stratosphere associated with the SSW that occurred on 9 February. Large standard deviations are also noted at the summer polar mesopause, with NAVGEM-HA and JAGUAR-DAS values exceeding $10 \mathrm{~K}$ and WACCMX+DART values exceeding $20 \mathrm{~K}$.

Figure 3 plots the DJF zonal mean zonal winds and temporal standard deviations from the four analyses (see also Fig. S2 in the Supplement). The general morphologies of the zonal mean zonal wind distributions in altitude and latitude are similar in all cases, exhibiting easterly (i.e., westward) flow in the summer hemisphere that tilts poleward with increasing altitude and westerly (i.e., eastward) flow in the winter hemisphere that tilts equatorward with increasing altitude. However, there are significant quantitative differences that likely warrant future investigation, the most prominent being the stronger peak winds in WACCMX+DART. These differences are likely due to inaccurate specification of the background winds in the model (e.g., Marsh et al., 2013, see their Fig. 1) and are most likely due to errors in the gravity wave parameterizations. This work shows that these known wind biases are not fully corrected by the assimilation of stratospheric and mesospheric temperature observations. For instance, WACCMX+DART exhibits an easterly jet that exceeds $80 \mathrm{~m} \mathrm{~s}^{-1}$ in the upper stratosphere and lower mesosphere $(\sim 50-60 \mathrm{~km})$ between the Equator and $30^{\circ} \mathrm{S}$ latitude, whereas the analogous easterly jet in the other models is weaker and more variable (as indicated by the standard deviation contours). Likewise, the westerly jet in the $\mathrm{NH}$ midlatitude upper stratosphere and mesosphere $(\sim 50$ $80 \mathrm{~km}$ ) is stronger in WACCMX+DART than in the other simulations. Differences are even more pronounced above $80 \mathrm{~km}$. WACCMX+DART shows a westerly jet in the Southern Hemisphere (SH) that peaks near $35-50^{\circ} \mathrm{S}$ and 100 $105 \mathrm{~km}$ altitude, with wind speeds $>70 \mathrm{~m} \mathrm{~s}^{-1}$. Although both NAVGEM-HA and JAGUAR-DAS do exhibit westerly winds in the SH above $80 \mathrm{~km}$, they are weaker than in WACCMX+DART in the respective regions of overlap (up to $95 \mathrm{~km}$ in NAVGEM-HA and $105 \mathrm{~km}$ in JAGUARDAS). Particularly notable is that even though JAGUARDAS extends to $\sim 105 \mathrm{~km}$, the SH westerly winds at this altitude only reach $\sim 25 \mathrm{~m} \mathrm{~s}^{-1}$, more than $40 \mathrm{~m} \mathrm{~s}^{-1}$ slower than in WACCMX+DART. An exception to the stronger peak winds in WACCMX+DART is evident in the NH lower thermosphere ( $\sim 90-105 \mathrm{~km}$ altitude) from 0 to $50^{\circ} \mathrm{N}$ latitude, where JAGUAR-DAS shows a strong easterly jet $\left(>40 \mathrm{~m} \mathrm{~s}^{-1}\right.$ near $30^{\circ} \mathrm{N}$ ); but WACCMX+DART easterlies in the $\mathrm{NH}$ lower thermosphere are weaker and shifted to higher latitudes. Finally, in the tropical lower stratosphere, NAVGEMHA, MERRA-2, and JAGUAR-DAS capture the alternating easterly and westerly flow related to the QBO, while WACCMX+DART shows easterly flow throughout the tropical stratosphere.

Examining the standard deviations in the DJF zonal mean winds in Fig. 3, we see that NAVGEM-HA, MERRA-2, and JAGUAR-DAS all exhibit similar variability along the equatorward flank of the summer easterly jet, but this variability is not present in WACCMX+DART. In the NH winter stratosphere, all four data sets exhibit similar variability associated with the stratospheric polar night jet. Above $80 \mathrm{~km}$, the major difference is the large variability in WACCMX+DART zonal mean zonal winds in the lower thermosphere between $30^{\circ}$ and $50^{\circ} \mathrm{S}$, coincident with the strong westerly jet.

The results in Figs. 2 and 3 show that the largest differences occur above $80 \mathrm{~km}$, where effects of gravity wave drag play an important role in determining the climatological zonal mean distributions of temperature and zonal wind in the middle atmosphere. Specific features such as the latitude and altitude dependences of the mesospheric summer easterly jet and the cold summer polar mesopause are known to be sensitive to the effects of gravity wave breaking and subsequent deposition of heat and momentum into the background (zonal mean) state (e.g., Fritts and Alexander, 2003). Some of the largest differences among the standard deviations in both zonal mean temperature and zonal mean zonal 


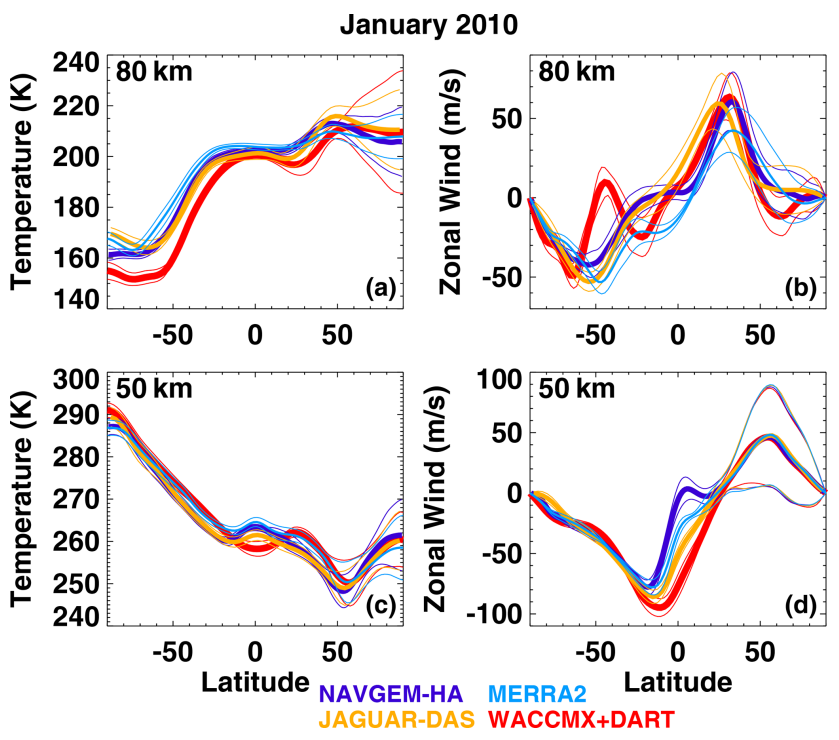

Figure 4. Latitude dependence of January 2010 average zonal mean temperature $(\mathbf{a}, \mathbf{c})$ and zonal wind $(\mathbf{b}, \mathbf{d})$ at $80 \mathrm{~km}$ (top) and $50 \mathrm{~km}$ (bottom) for NAVGEM-HA (purple), MERRA-2 (light blue), JAGUAR-DAS (gold), and WACCMX+DART (red). Thick curves indicate the monthly zonal mean values, and thin curves indicate \pm 1 standard deviation of the daily means.

wind plotted in Figs. 2 and 3 occur in the vicinity of these features, suggesting that differences in the treatment of gravity wave drag may be an important factor for explaining the large differences among the analyses above $80 \mathrm{~km}$. Indeed, Pedatella et al. (2014a) showed that gravity wave drag differences among models is related to differences in the background winds. The cause of the temperature and zonal wind differences presented here requires further investigation that is beyond the scope of this initial intercomparison study.

To further examine the differences in zonal mean temperature and zonal wind distributions among the four analyses, Fig. 4 plots the latitude distribution of zonal mean temperature (left column) and zonal mean zonal wind (right column) at $80 \mathrm{~km}$ (top) and $50 \mathrm{~km}$ (bottom) averaged over January 2010, when the variability in the NH winter zonal mean winds and temperatures in the mesosphere was largest due to the occurrence of the SSW. To evaluate differences in the intrinsic variability in these quantities during $\mathrm{NH}$ winter, Fig. 4 also shows standard deviations of the January mean as a function of latitude. At $50 \mathrm{~km}$ altitude (Fig. 4, bottom row), we find that the zonal mean temperature and zonal wind values among the four analyses are in very good agreement in the SH (summer) extratropics, where the dayto-day variability throughout the month is relatively small. Near the Equator, the temperatures at $50 \mathrm{~km}$ differ by $8-10 \mathrm{~K}$, with MERRA-2 and NAVGEM-HA tending to be warmer and WACCMX+DART tending to be cooler. However, there is a very large spread $\left(\sim 80-100 \mathrm{~m} \mathrm{~s}^{-1}\right)$ among the January mean zonal winds at $50 \mathrm{~km}$ within the tropics, with
NAVGEM-HA exhibiting weak westerly winds at the Equator and WACCMX+DART exhibiting strong easterly winds. These differences in equatorial zonal mean zonal wind at $50 \mathrm{~km}$ among the four analyses are much larger than the day-to-day variability indicated by the corresponding standard deviation values, suggesting a systematic bias could be present among these data sets. At NH extratropical latitudes, all four analyses produce similar mean values, and the spread among the mean results is much smaller than the standard deviations. The large standard deviations in the extratropical $\mathrm{NH}$ (winter) at $50 \mathrm{~km}$ reflect the high degree of day-to-day variability due to strong PW forcing in late January that resulted in a major SSW on 9 February.

In contrast to the results at $50 \mathrm{~km}$, at $80 \mathrm{~km}$ altitude (Fig. 4, top row), we find significant differences in both zonal mean temperature and zonal mean zonal wind values throughout the extratropical SH. Most notably, WACCMX+DART exhibits temperatures up to $\sim 20 \mathrm{~K}$ cooler near $70^{\circ} \mathrm{S}$ and weak westerly winds near $50^{\circ} \mathrm{S}$, in contrast to strong easterlies in MERRA-2, NAVGEM-HA, and JAGUAR-DAS. Similar to the results at $50 \mathrm{~km}$, the equatorial zonal mean zonal winds at $80 \mathrm{~km}$ also exhibit considerable spread, and these differences are larger than the temporal standard deviation during January 2010. The large differences in equatorial zonal winds at both 50 and $80 \mathrm{~km}$ highlight the challenge of producing wind analyses in a region where geostrophic balance constraints used by DA systems (see, e.g., Eckermann et al., 2018, their Fig. 4) to relate wind information to the satellite-based middle atmosphere temperature observations (e.g., MLS, SABER) begin to break down.

In addition to the monthly and seasonally averaged results presented in Figs. 2-4, comparisons of the daily variability in zonal mean temperatures and zonal winds are of interest because the 2009-2010 NH winter was so dynamically active. The major SSW that took place on 9 February 2010 was preceded by a reversal in mesospheric flow from westerly to easterly beginning on 27 January, which then descended to the stratosphere (McCormack et al., 2017). This mesospheric wind reversal effectively filters out upwardpropagating gravity waves with westward phase speeds through the formation of a critical line, thereby dramatically reducing dynamical heating via gravity wave breaking in the $\mathrm{NH}$ polar mesosphere. The result is the well-documented "sudden mesospheric cooling" that accompanies most SSW events (e.g., Matsuno, 1971; Labitzke, 1972; Siskind et al., 2010; Eswaraiah et al., 2017). It has been suggested that the abrupt changes in NH (winter) polar gravity wave breaking can have consequences for SH (summer) polar mesopause temperatures through changes in the pole-to-pole meridional residual circulation produced by subsequent modulation of the gravity wave drag in both the winter and summer mesosphere (e.g., Karlsson and Becker, 2016; Laskar et al., 2019; Zülicke et al., 2018). The combined effects of these SSWrelated changes in mesospheric gravity wave drag produce an anomalous residual circulation with weaker upwelling in 


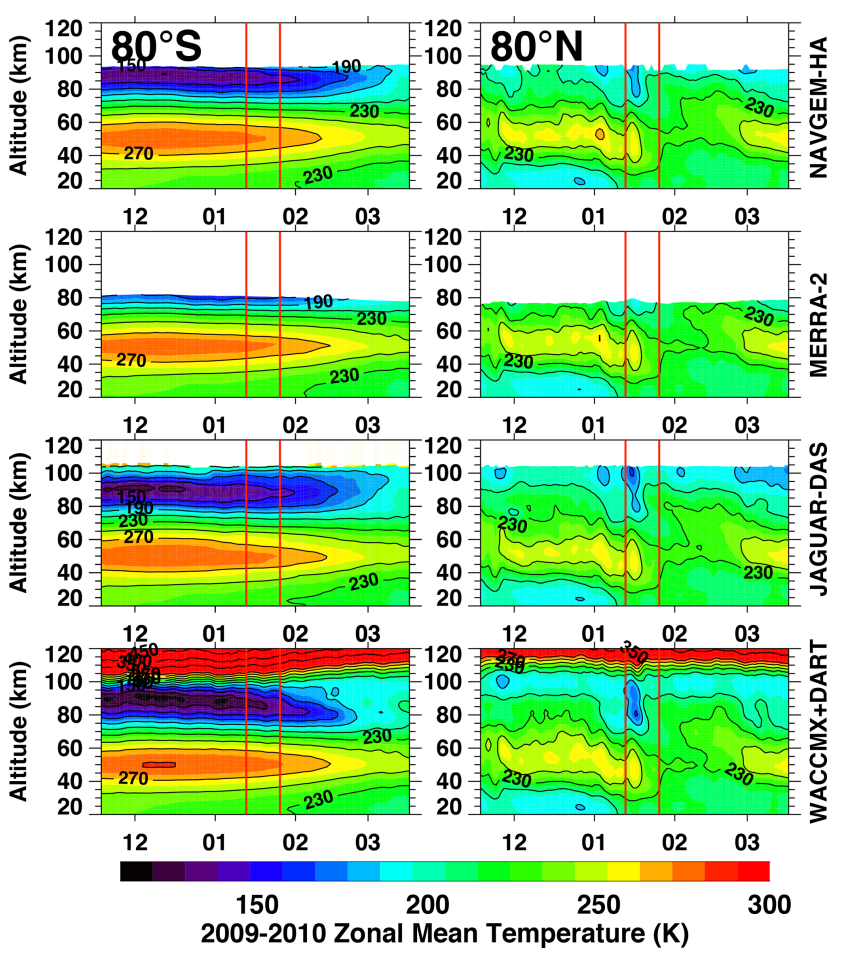

Figure 5. Altitude-time cross-sections from 1 December 2009 to 31 March 2010 of daily mean zonal mean temperature in NAVGEM-HA, MERRA-2, JAGUAR-DAS, and WACCMX+DART at $80^{\circ} \mathrm{S}$ (left column) and $80^{\circ} \mathrm{N}$ (right column). Vertical red lines in each panel denote 27 January (the onset of sustained easterly flow in the mesosphere) and 9 February (the onset of easterly flow in the stratosphere), as described in the text. Month tick labels along the $x$ axes are placed at the 15th of each month.

the summer polar mesopause region and thus warmer temperatures in this region due to a reduction in adiabatic cooling. Alternatively, several case studies based on high-altitude meteorological analyses suggest that changes in mesospheric Q2DW activity may play a role in interhemispheric coupling (e.g., Siskind and McCormack, 2014; France et al., 2018; Lieberman et al., 2021). An additional mechanism was discussed in Smith et al. (2020), in which changes in summer polar mesopause temperatures are a response to changes in the residual meridional circulation, with no direct role for wave activity in the summer hemisphere.

The relationship between winter mesospheric cooling and summer polar mesopause warming for the 2009-2010 NH winter period is examined in Fig. 5, which plots the time behavior of daily averaged zonal mean temperatures at $80^{\circ} \mathrm{S}$ (left column) and $80^{\circ} \mathrm{N}$ (right column) from 1 December 2009 to 31 March 2010. There are two key dates highlighted in each panel. The left vertical red line denotes 27 January 2010 , the first day of sustained ( $>5 \mathrm{~d}$ ) mesospheric easterly winds at $60^{\circ} \mathrm{N}$ (McCormack et al., 2017). Easterly winds in the upper stratosphere have been shown to be an effective proxy to explore mesospheric and lower thermospheric effects following SSWs (Jones et al., 2018; Limpasuvan et al. 2016; Stray et al., 2015; Tweedy et al., 2013). The right vertical red line indicates 9 February 2010, the onset of easterly winds in the stratosphere (Butler et al., 2017). These two dates are highlighted throughout the paper to denote the disturbed stratospheric and mesospheric time period. At $80^{\circ} \mathrm{N}$ (right column), all four analyses agree with respect to the timing of the SSW, and the three analyses that extend above $80 \mathrm{~km}$ altitude also show similar timing of the mesospheric cooling. We note that the winter mesopause is at $\sim 90-95 \mathrm{~km}$ in NAVGEM-HA but is near $100 \mathrm{~km}$ in both JAGUAR-DAS and WACCMX+DART. At $80^{\circ} \mathrm{S}$ (left column) the main differences are in the minimum temperature values from 85 to $95 \mathrm{~km}$ altitude, where the NAVGEM-HA minimum value is $\sim 140 \mathrm{~K}$, the JAGUAR-DAS minimum value is $\sim 130 \mathrm{~K}$, and the WACCMX+DART minimum value is $\sim 120 \mathrm{~K}$. The lower altitude and warmer temperatures at the high southern latitudes in NAVGEM-HA may be a consequence of the lower model top. There are also differences in the seasonal evolution of the cold summer polar mesopause, most notably the downward progression of the temperature minimum in WACCMX+DART during January and February, which is not seen in either NAVGEM-HA or JAGUAR-DAS. None of the high-altitude analyses show a clear relationship between the onset of the mesospheric cooling at $80^{\circ} \mathrm{N}$ and an increase in summer polar mesopause temperatures at $80^{\circ} \mathrm{S}$ that would indicate a direct interhemispheric coupling (IHC) mechanism as described above, although we note that previous studies found the temperature response in the summer mesopause region to be relatively small, $\sim 2-5 \mathrm{~K}$ (e.g., Karlsson et al., 2009a; deWit et al., 2015). Further examination of output from these analyses for other SSW cases in conjunction with modeling studies is needed to fully explore possible links between summer polar mesopause warmings and middle atmospheric variability in $\mathrm{NH}$ winter.

Similar to the zonal mean temperature results in Fig. 5, all four analyses exhibit similar temporal behavior in the zonal mean zonal winds at $60^{\circ} \mathrm{N}$ (Fig. 6, right column) during the 2009-2010 winter period up to $\sim 70 \mathrm{~km}$ altitude, capturing both the sudden reversal of mesospheric winds in late January and the downward descent of easterly zonal winds into the stratosphere. Above $70 \mathrm{~km}$ altitude, the main differences are the presence of weak westerly flow in NAVGEMHA, JAGUAR-DAS, and MERRA-2 (up to $80 \mathrm{~km}$ ), whereas WACCMX+DART produces easterly flow above $70 \mathrm{~km}$ with maximum values exceeding $-30 \mathrm{~m} \mathrm{~s}^{-1}$ from 80 to $100 \mathrm{~km}$ altitude. At $60^{\circ} \mathrm{S}$ (Fig. 6, left column), all four analyses show an easterly jet centered near $75 \mathrm{~km}$ altitude in December 2009. Above this level, WACCMX+DART shows much larger vertical wind shear compared to NAVGEM-HA and JAGUAR-DAS and a rapid transition to strong westerly flow exceeding $60 \mathrm{~m} \mathrm{~s}^{-1}$ in the lower thermosphere. Since the deceleration and reversal of the easterly summer mesospheric jet is related to strong eastward gravity wave drag, differ- 

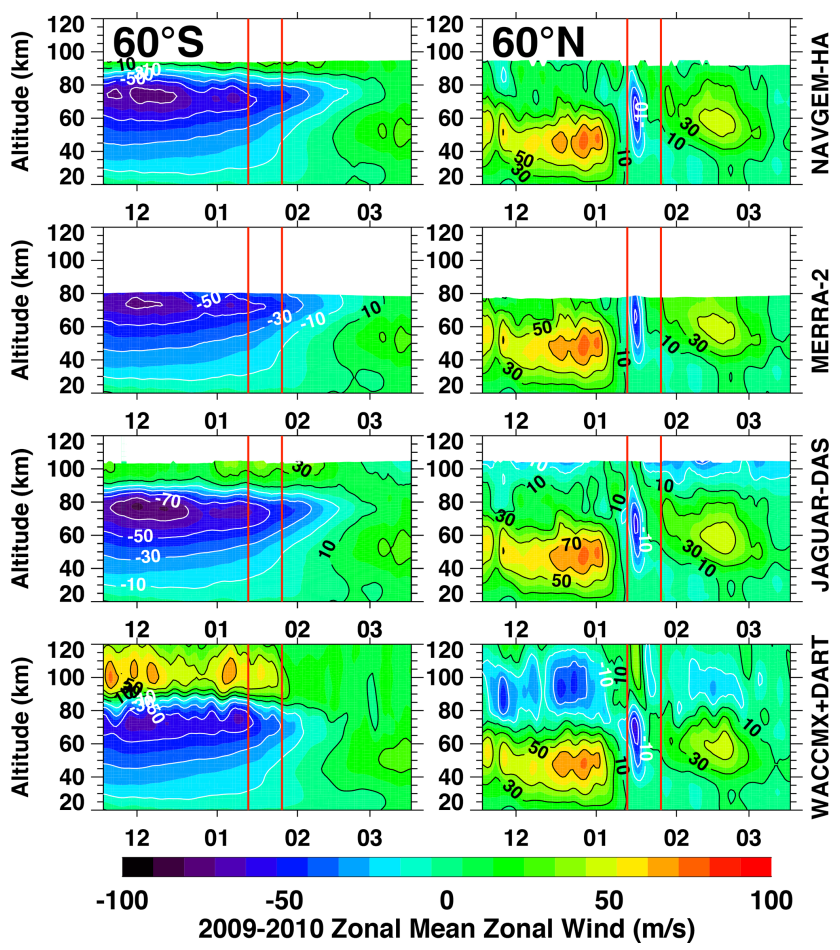

Figure 6. As in Fig. 5 but for zonal wind at $60^{\circ} \mathrm{S}$ (left) and $60^{\circ} \mathrm{N}$ (right).

ing treatments of gravity wave drag among the various systems, most notably in WACCMX+DART, may be responsible for the differences in the vertical structure of the easterly summer jet at $60^{\circ} \mathrm{S}$ in Fig. 6. Further investigation of this would require detailed momentum budget studies using specific output data (e.g., wind tendencies due to parameterized wave drag) that are not available for the present study. Making this data part of standard meteorological output fields would facilitate future investigations into the specific role that gravity wave drag plays in explaining these differences among the mesospheric zonal wind analyses.

To further explore the global response of middle atmospheric zonal mean zonal winds and temperatures to the occurrence of the SSW and mesospheric cooling in the $\mathrm{NH}$ winter of 2009-2010, we next examine the latitude-time distributions of zonal mean temperature and zonal mean zonal wind for three altitudes (50, 70, and $90 \mathrm{~km})$ in Figs. 7 and 8 , respectively, from the four analyses. Overall, we find good qualitative and quantitative agreement among the zonal mean temperatures at $50 \mathrm{~km}$ (Fig. 7, bottom row). We note that NAVGEM-HA and MERRA-2, which assimilate MLS stratospheric $\mathrm{O}_{3}$ profiles, exhibit slightly lower peak temperatures at the South Pole compared to JAGUARDAS and WACCMX+DART, which do not assimilate stratospheric $\mathrm{O}_{3}$ observations. It would be of interest for future work to examine how differences in the assimilation of radiatively active chemical constituents such as $\mathrm{O}_{3}$ and

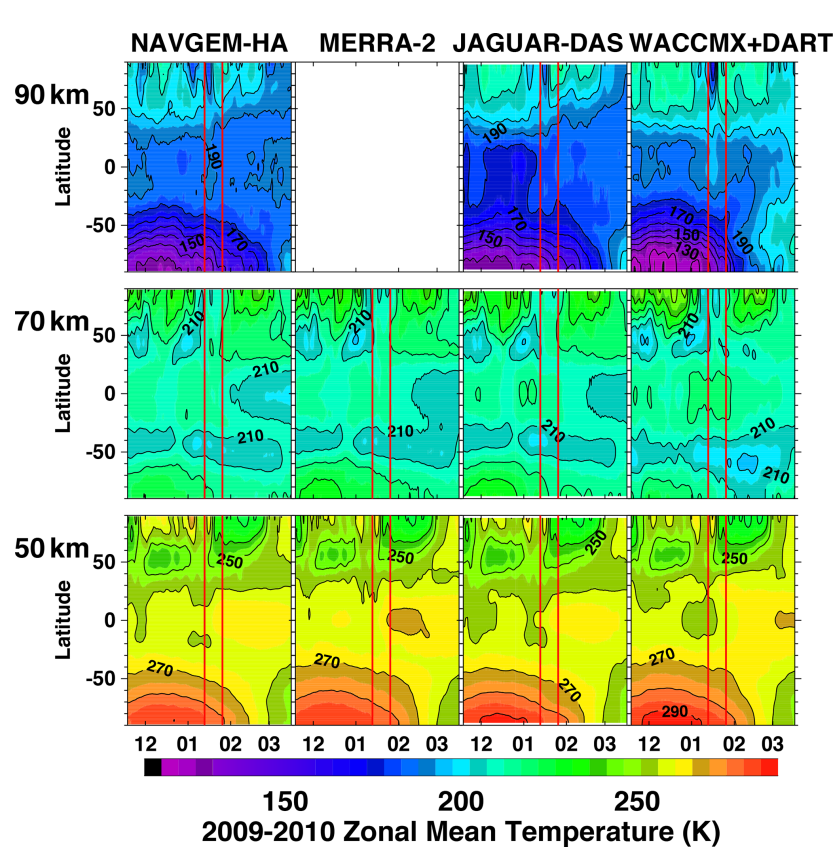

Figure 7. Latitude-time cross-sections from 1 December 2009 to 31 March 2010 of daily mean zonal mean temperature in NAVGEM-HA, MERRA-2, JAGUAR-DAS, and WACCMX+DART at $90 \mathrm{~km}$ (top), $70 \mathrm{~km}$ (middle), and $50 \mathrm{~km}$ (bottom). Contours are drawn every $20 \mathrm{~K}$. Vertical red lines in each panel denote 27 January and 9 February, as described in the text. Month tick labels along the $x$ axes are placed at the 15th of each month.

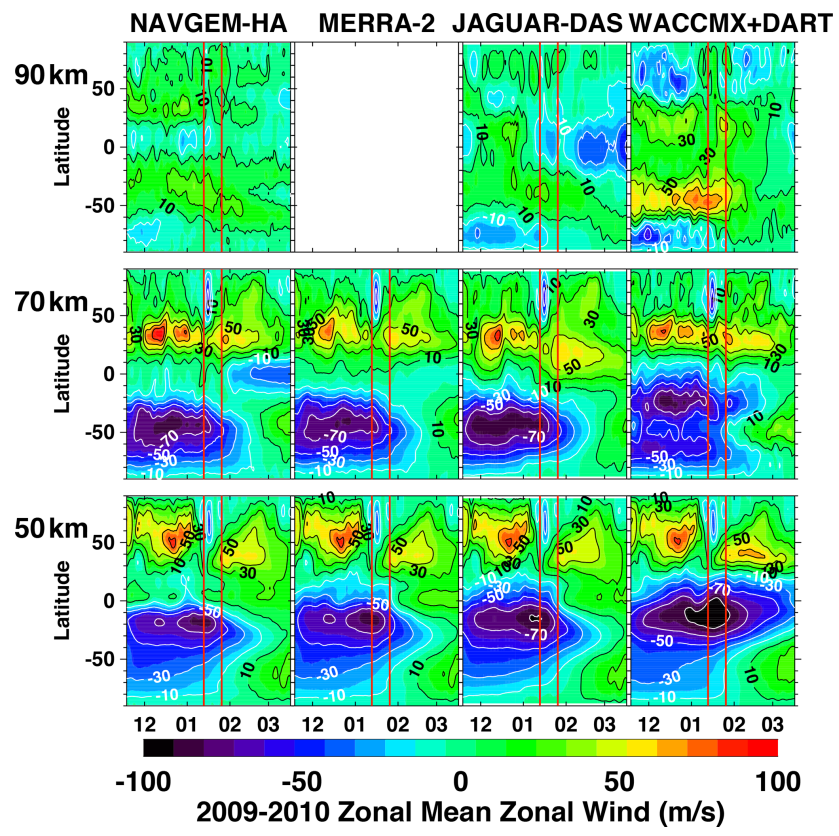

Figure 8. As in Fig. 7 but for zonal wind. Contours are drawn every $20 \mathrm{~ms}^{-1}$. 
$\mathrm{H}_{2} \mathrm{O}$ impact the agreement among different middle atmospheric meteorological analyses. At $70 \mathrm{~km}$ altitude (Fig. 7 , middle row), there is generally good qualitative agreement among the four analyses. Notable quantitative differences are the comparatively warmer temperatures in the equatorial region and the comparatively colder temperatures from 50 to $90^{\circ} \mathrm{S}$ during late February and March in WACCMX+DART. At $90 \mathrm{~km}$ altitude (Fig. 7, top row), we again find generally consistent qualitative behavior but with some important quantitative differences. Specifically, NAVGEM-HA shows a pronounced mesospheric cooling in the NH extratropics in mid-December that is not present in the JAGUARDAS or WACCMX+DART results. JAGUAR-DAS equatorial temperatures are 10-15 K colder than NAVGEM-HA or WACCMX+DART. At the South Pole, WACCMX+DART temperatures are $20-30 \mathrm{~K}$ colder than NAVGEM-HA or JAGUAR-DAS. While all three high-altitude analyses show the mesospheric cooling prior to the major SSW in early February 2010, only NAVGEM-HA and WACCMX+DART indicate a related warm anomaly in the equatorial regions.

The latitude-time distributions of zonal mean zonal wind, shown in Fig. 8, also generally show good qualitative agreement among the four analyses regarding the timing of the wind reversals in the NH extratropics related to the SSW and mesospheric cooling seen in Fig. 7. Notable differences in the behavior of the zonal mean zonal winds include the following: the very strong and persistent easterly flow in the equatorial regions at $50 \mathrm{~km}$ altitude (Fig. 8, bottom row) seen in WACCMX+DART; the emergence of tropical easterly flow in late February and March at $70 \mathrm{~km}$ altitude (Fig. 8, middle row) in NAVGEM-HA and the split summer easterly jet in the SH seen in WACCMX+DART; and easterly winds over the Equator at $90 \mathrm{~km}$ altitude (Fig. 8, top row) in the JAGUAR-DAS results and the strong westerly flow in the WACCMX+DART results near $40^{\circ} \mathrm{S}$, which was also noted in the discussion of DJF average results (Fig. 3, bottom right panel). These zonal wind differences in the upper stratosphere and mesosphere are likely attributed to differences in the treatment of gravity wave drag in each system, though specific origins require further investigation, as noted above. Users of these high-altitude meteorological analyses should be aware that these differences in the zonal mean zonal winds imply that the choice of meteorological inputs may impact the results of nudged whole atmosphere simulations.

Next we explore global temperature variations during the 2 weeks preceding the major SSW event. Figure 9 shows latitude-altitude plots of the correlation coefficient between daily mean temperature variations at $80^{\circ} \mathrm{N}$ and $30 \mathrm{~km}$ and corresponding temperature variations at other latitudes and altitudes during 27 January to 9 February 2010 in the four analyses. As expected, all four systems show positive correlations (warming) in the $\mathrm{NH}$ polar stratosphere, evidence that they all simulate the SSW event. Likewise, all four systems show negative correlations (cooling) in the $\mathrm{NH}$ polar mesosphere; this demonstrates that mesospheric cooling is also re-
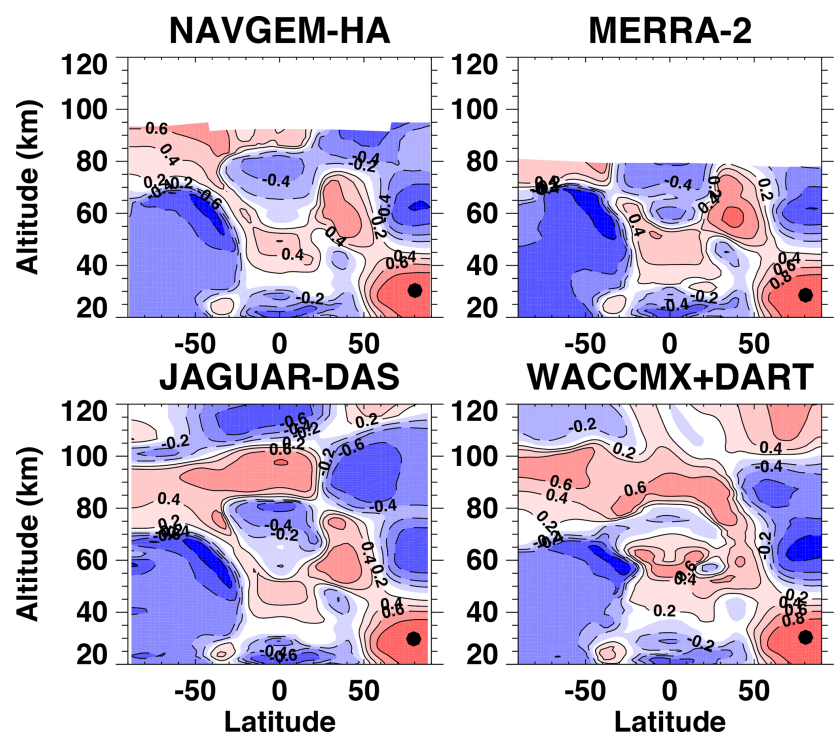

Figure 9. Latitude-altitude cross-sections of the correlation coefficient between daily zonal mean temperature at $30 \mathrm{~km}$ and $80^{\circ} \mathrm{N}$ (indicated by the black-filled symbol) and daily zonal mean temperature at all other latitudes and altitudes in NAVGEM-HA, MERRA-2, JAGUAR-DAS, and WACCMX+DART. Correlation values equal 1 at the location of the black-filled symbols at $30 \mathrm{~km}$ and $80^{\circ} \mathrm{N}$. Negative (positive) values are contoured every 0.2 using dashed (solid) black lines. The SSW disturbance time period over which the correlation coefficient is calculated is from 27 January to 9 February.

liably captured in all systems. Similar connections between the SSW and polar mesospheric temperatures have been noted in previous observational studies using MLS temperature data (e.g., Zülicke et al., 2018). However, Fig. 9 indicates that there are also consistent correlation coefficient patterns that extend into the deep tropics and into the SH among the four systems. All four systems show vertically alternating negative and positive correlation regions in the tropics and subtropics of both hemispheres. All four systems show negative correlations (cooling) in the SH polar stratosphere and lower mesosphere and positive correlations (warming) poleward of $40^{\circ} \mathrm{S}$ between $\sim 75$ and $95 \mathrm{~km}$, consistent with interhemispheric coupling relationships reported by Karlsson et al. (2009b). The agreement in temperature variability among the systems in the NH polar stratosphere and mesosphere is expected. However, the agreement in temperature variations among the systems in the tropics and in the summer hemisphere, even extending into the upper mesosphere, demonstrates that the four analyses capture similar temporal behavior globally despite the mean differences shown earlier.

To examine the range in zonal mean temperatures and zonal winds, Figs. 10 and 11 plot the standard deviations in the daily mean values of each quantity among the four analyses (three at $90 \mathrm{~km}$ where MERRA-2 is unavailable). Fig. 10 shows that all the analyses are in fairly good quantitative 


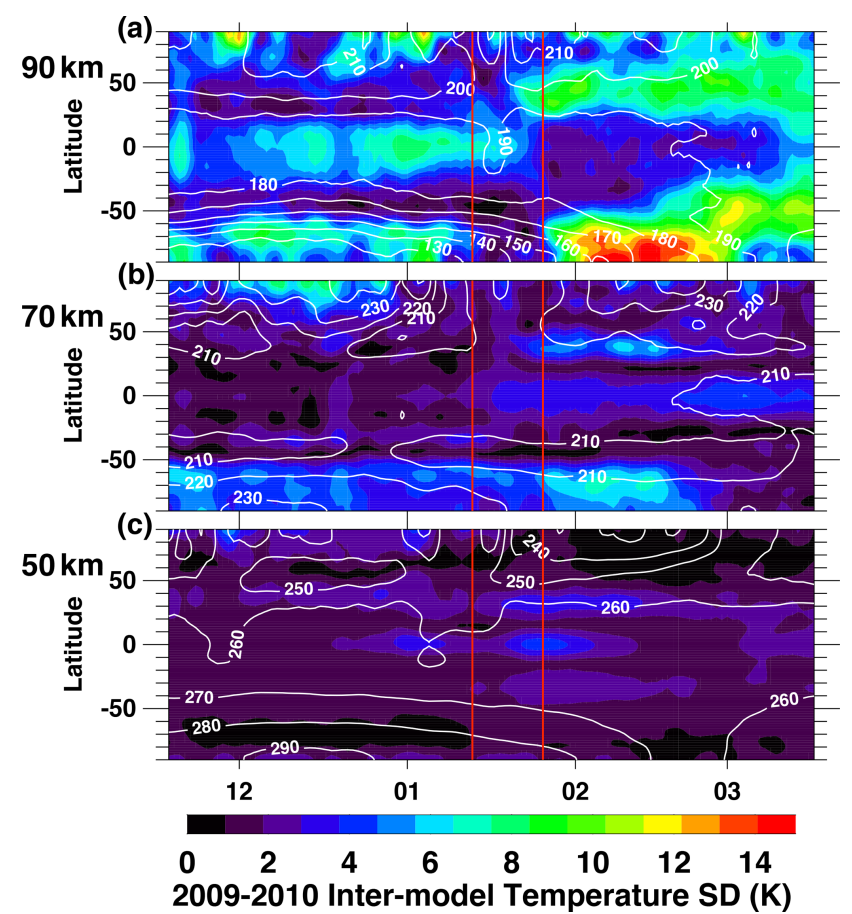

Figure 10. Latitude-time cross-sections from 1 December 2009 to 31 March 2010 of the standard deviation in daily mean zonal mean temperature among the meteorological data sets at $90 \mathrm{~km}$ (top), $70 \mathrm{~km}$ (middle), and $50 \mathrm{~km}$ (bottom). There is no MERRA-2 data at $90 \mathrm{~km}$. For reference, white contours indicate the mean values among the data sets. Vertical red lines in each panel denote 27 January and 9 February, as described in the text. Month tick labels along the $x$ axes are placed at the 15th of each month.

agreement with regards to temperature at 50 and $70 \mathrm{~km}$ altitude, but deviations of $10 \mathrm{~K}$ or more are common at $90 \mathrm{~km}$, with the largest disagreement occurring at the South Pole at the end of summer. Similarly, Fig. 11 shows that zonal wind deviations among the data sets are generally $5 \mathrm{~m} \mathrm{~s}^{-1}$ or less outside of the equatorial regions at 50 and $70 \mathrm{~km}$, but larger deviations in excess of $20 \mathrm{~m} \mathrm{~s}^{-1}$ emerge at $90 \mathrm{~km}$ both in the tropics and near $50^{\circ}$ latitude in both hemispheres. Overall, the largest zonal mean zonal wind deviations $\left(>35 \mathrm{~m} \mathrm{~s}^{-1}\right)$ occur not at the higher altitudes but at $50 \mathrm{~km}$ altitude during February and March 2010 (Fig. 11, bottom panel). The results in Fig. 11 indicate that these high-altitude analyses do not yet produce a consistent representation of the semiannual oscillation (SAO) in zonal mean zonal winds in the equatorial middle atmosphere (Kawatani et al., 2020). The SAO is a basic climatological feature of the middle atmospheric circulation that impacts the propagation of gravity waves and tides into the mesosphere and lower thermosphere (e.g., Garcia et al., 1997). Consequently, this is an issue that will need to be addressed as these high-altitude data assimilation systems evolve.

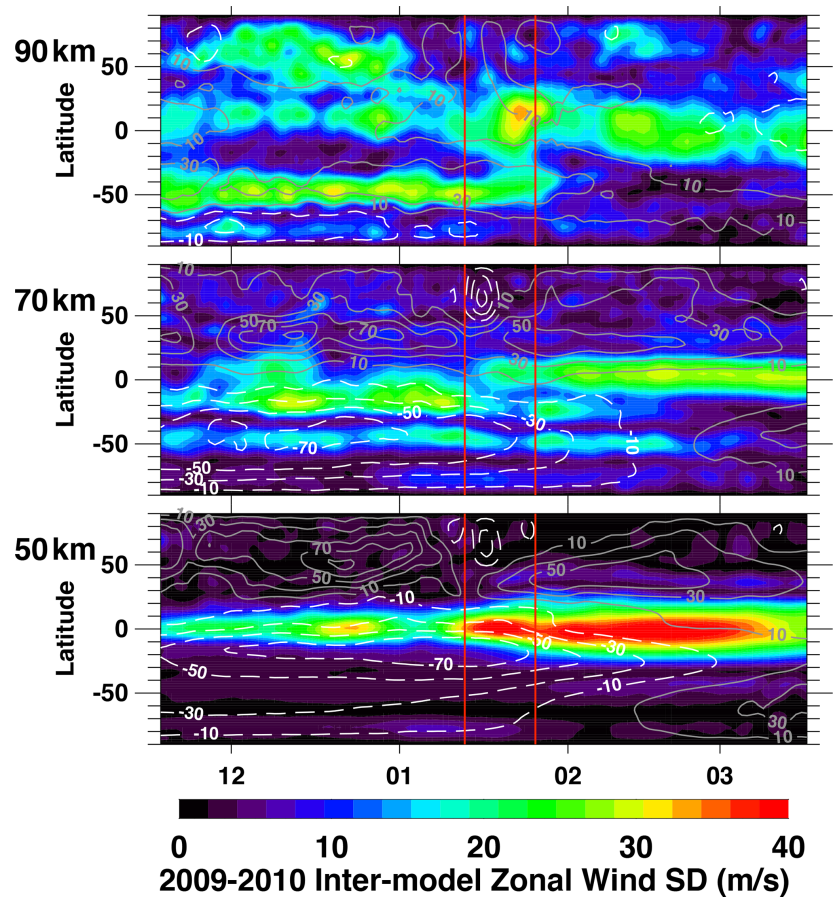

Figure 11. As in Fig. 10 but for zonal wind standard deviation among the analyses. For reference, dashed white and solid gray contours indicate the mean easterly and westerly winds, respectively, among the data sets. Contours are drawn every $20 \mathrm{~ms}^{-1}$.

\section{Planetary wave and tide results}

In addition to zonal mean quantities, these four middle atmosphere meteorological analyses also provide valuable information on zonal variations in temperature and winds related to planetary-scale waves and tides, which earlier studies based on MLS (e.g., Forbes and Wu, 2006) and SABER (e.g., Garcia et al., 2005; Zhang et al., 2006) temperature observations found to be prevalent throughout the MLT. Since each of the four analyses examined here assimilate either MLS data, SABER data, or a combination of the two, this section examines how these features are captured in each of the reanalyses. To begin, Fig. 12 plots longitude-time variations in daily mean temperature at $60^{\circ} \mathrm{N}$ and $70 \mathrm{~km}$ altitude from 1 December 2009 to 31 March 2010. At this altitude, there is good agreement in the zonal variations in temperature among the four analyses, which all show a strong quasi-stationary zonal wave number 1 during December 2009 and January 2010, which then abruptly shifts to a slowly westward-propagating wave number 1 feature in early February that persists through March. The timing of this shift appears to coincide with the reversal of mesospheric winds on 27 January, 2 weeks before the major SSW, as shown in Fig. 6. We note that the quasi-stationary and traveling PW amplitudes are larger in WACCMX+DART relative to the NAVGEM-HA, MERRA-2, and JAGUAR-DAS results. Abrupt shifts in quasi-stationary planetary wave 1 in 


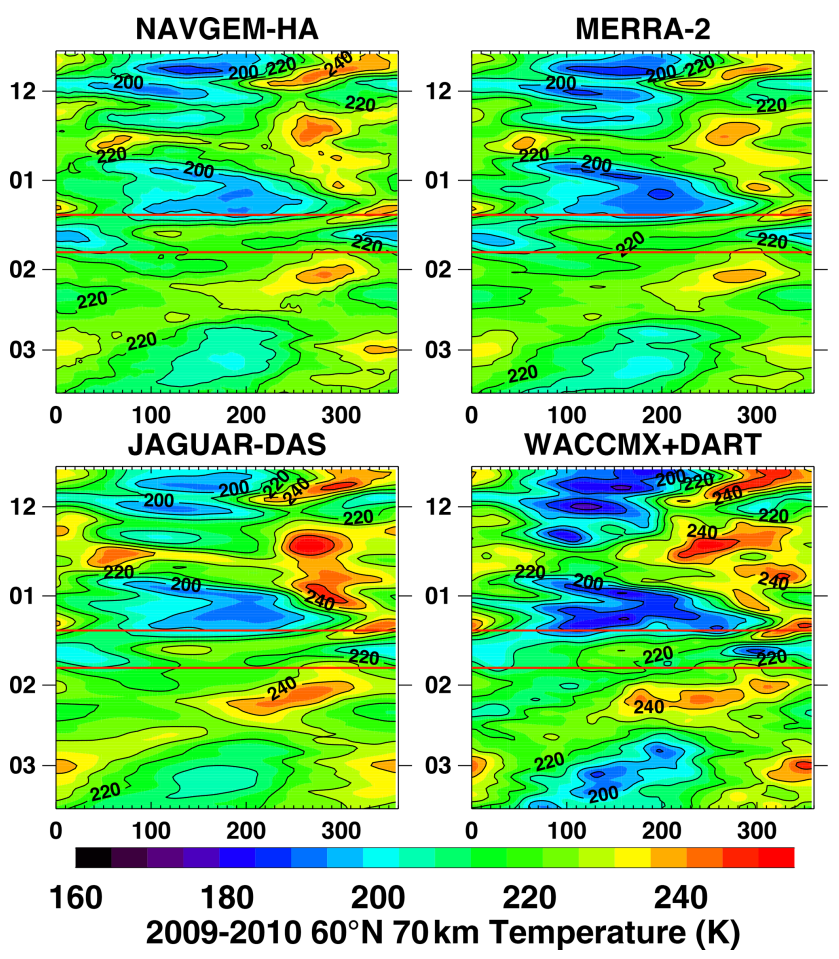

Figure 12. Longitude-time Hovmöller diagrams at $60^{\circ} \mathrm{N}$ and $70 \mathrm{~km}$ from 1 December 2009 to 31 March 2010 of daily mean temperature in NAVGEM-HA, MERRA-2, JAGUAR-DAS, and WACCMX+DART. Horizontal red lines in each panel denote 27 January and 9 February, as described in the text. Month tick labels along the $y$ axes are placed at the 15th of each month.

the northern high latitude winter mesosphere related to SSWs have been documented in numerous studies (e.g., Smith, 2003; Manney et al., 2008; Siskind et al., 2010; Chandran et al., 2013; Koushik et al., 2020) and are linked to highly episodic sources of barotropic/baroclinic instability at $\mathrm{NH}$ middle and high latitudes within the upper stratosphere and mesosphere (Sassi and Liu, 2014). Future studies comparing the relative roles of resolved vs. parameterized gravity wave forcing of the mesospheric circulation, as well as the representation of baroclinic/barotropic instabilities, within the four analyses could lend insight into the origins of the differences in Fig. 12 and would help to improve our understanding of this phenomenon as it relates to changes in the state of the T-I system in connection to SSWs.

In the remainder of this section, we present results from space-time analysis of the four analyses related to the Q5DW, Q2DW, DW1, SW2, and DE3 features. Recognizing that many other planetary wave and tidal features (e.g., Forbes et al., 2008; Sassi et al., 2012) are also important for producing T-I variability related to meteorological forcing from the middle atmosphere (McDonald et al., 2018), the present study is not meant to be an all-inclusive assessment of every feature but rather is meant to provide an initial extension of the intercomparison study by Harvey et al. (2021) to include the mesosphere and lower thermosphere.

We begin with an examination of the Q5DW, which consists of a westward-propagating zonal wave number 1 disturbance related to the first hemispherically symmetric normal (Rossby) mode. As shown in Harvey et al. (2021), the middle atmospheric Q5DW can manifest in two forms: first, as a hemispherically symmetric feature related to latent heat release in the tropical upper troposphere (Salby, 1981; Miyoshi and Hirooka, 2003) peaking between 30 and $50^{\circ}$ latitude in the summer hemisphere; and second, as a high latitude wintertime feature related to growth through baroclinic/barotropic instability, leading to what is commonly referred to as the $6.5 \mathrm{~d}$ wave in the mesosphere and lower thermosphere (Talaat et al., 2001; Lieberman et al., 2003; Forbes and Zhang, 2017). Given the complex dynamical interactions that give rise to the Q5DW, capturing this feature is a good test for middle atmospheric meteorological analyses. Figure 13 plots altitude and latitude dependences of the Q5DW amplitude in temperature during January 2010 extracted from the four analyses using the 2DFFT method described in Sect. 2 and using a bandpass for westward zonal wave number 1 and $0.16-0.24 \mathrm{cpd}$ (periods of 4.25-6 d). In all four analyses, the dominant Q5DW pattern is the highlatitude winter feature with peak amplitudes of $2-3 \mathrm{~K}$ between 60 and $80^{\circ} \mathrm{N}$ latitude. These amplitudes are consistent with the $5 \mathrm{~d}$ Rossby normal mode variation of $2.5-3.5 \mathrm{~K}$ derived from SABER temperature observations in the study by Garcia et al. (2005) for the March-May 2002 period; they are also consistent with quasi- $6 \mathrm{~d}$ wave amplitudes at high northern latitudes in January reported by Forbes and Zhang (2017) using 14 years of SABER temperatures. The main difference in the Q5DW amplitudes among the data sets is its vertical extent. Both NAVGEM-HA and WACCMX+DART exhibit Q5DW amplitudes of 1-2 K at high northern latitudes above $80 \mathrm{~km}$, whereas the corresponding Q5DW amplitudes in JAGUAR-DAS are limited to below $80 \mathrm{~km}$ altitude. The three analyses extending above $80 \mathrm{~km}$ altitude also indicate weak (0.5-1 K) Q5DW amplitudes in the SH (summer) extratropics that may be related to convective latent heat release.

Similar to the Q5DW, the Q2DW is a well-documented feature of upper stratospheric and mesospheric dynamics (e.g., Coy, 1979; Harris, 1994; Limpasuvan and Wu, 2003; Garcia et al., 2005; Pancheva, 2006; Lilienthal and Jacobi, 2015; Kumar et al., 2018). The Q2DW consists primarily of a westward-propagating zonal wave number 3 , although westward wave number 2 and 4 components are also present in both satellite observations and high-altitude meteorological analyses (e.g., McCormack et al., 2009; Tunbridge et al., 2011; Gu et al., 2013; McCormack et al., 2014). In the mesosphere, the Q2DW originates primarily from regions of baroclinic instability in the easterly mesospheric summer jet (Plumb, 1983; Pfister, 1985) that form in part by the effects of gravity wave drag (e.g., Ern et al., 2013; Sato et al., 2018). In the tropical upper stratosphere, the Q2DW can 

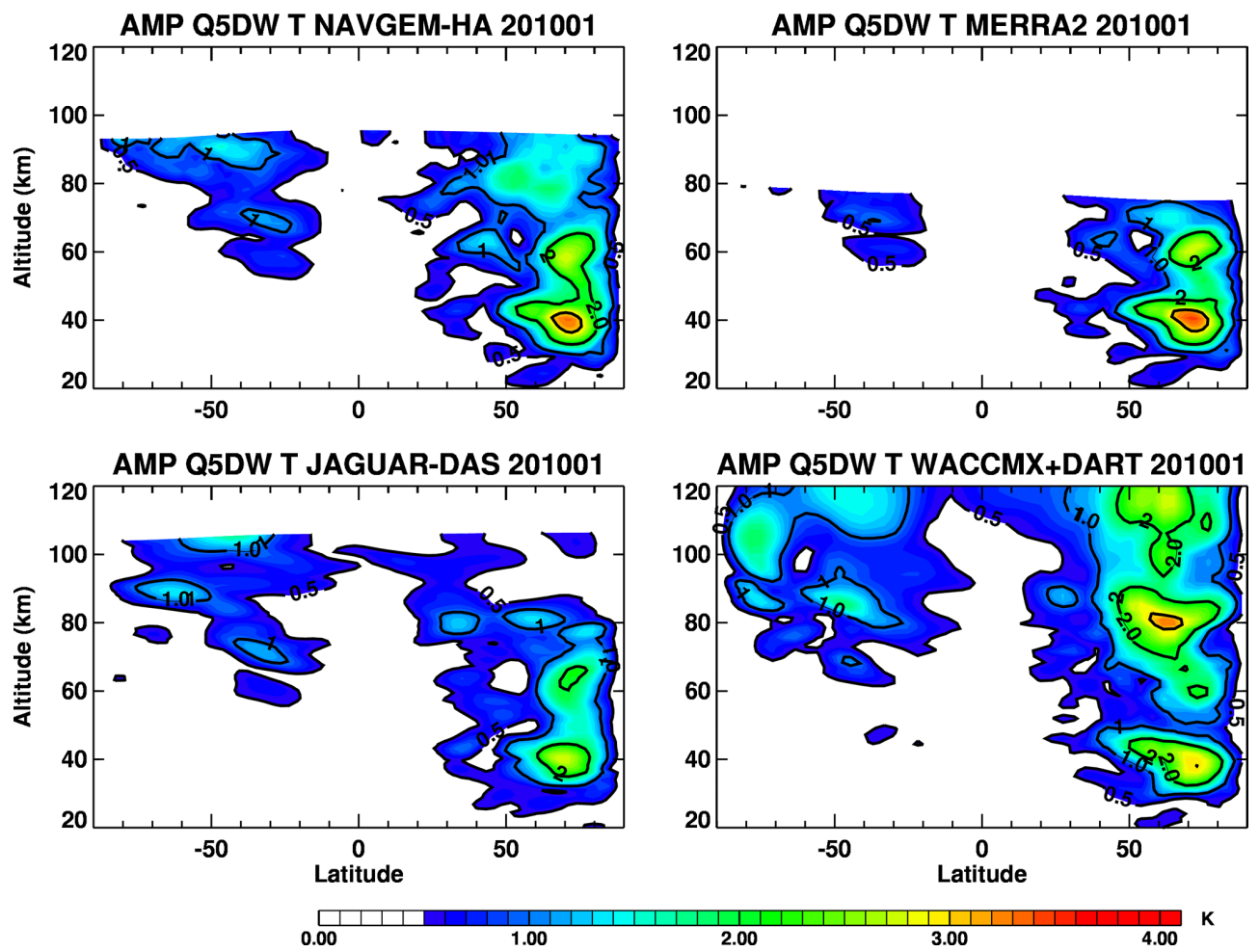

Figure 13. Monthly mean amplitude of the quasi-5d (Q5DW) wave in temperature for January 2010 from NAVGEM-HA, MERRA-2, JAGUAR-DAS, and WACCMX+DART.

originate from regions of barotropic instability (Burks and Leovy, 1986) related to inertial instability resulting from unusually strong PW activity in the winter hemisphere (e.g., Orsolini et al., 1997; McCormack et al., 2009; Lieberman et al., 2021). Both observational and modeling studies have indicated that the Q2DW, often through interaction with tides, is a significant source of day-to-day variability in the dynamics and composition of the thermosphere and ionosphere (e.g., Chang et al., 2011; Yue et al., 2012; Chang et al., 2014). It is, therefore, important that meteorological analyses used to constrain whole atmosphere simulations accurately capture the Q2DW.

Figure 14 plots altitude and latitude dependences of the January monthly mean Q2DW amplitude in temperature extracted from the four analyses using a bandpass for zonal wave number 3 and westward frequencies between 0.45 and $0.6 \mathrm{cpd}$ (periods of 1.6-2.2 d). Below $80 \mathrm{~km}$ altitude, all four analyses show the largest Q2DW amplitudes in the SH along the equatorward flank of the summer easterly jet (see Fig. 3), coinciding with the region where the standard deviations in zonal mean zonal wind are largest in SH summer (e.g., Figs. 3 and S2). This spatial structure is broadly consistent with results from earlier studies based on MLS (e.g., Limpasuvan and $\mathrm{Wu}, 2003$ ) and SABER (e.g., Gu et al., 2013) temperature observations. Peak amplitudes range between 2 and $3 \mathrm{~K}$ in three of the analyses (NAVGEM-HA, MERRA2 , and JAGUAR-DAS) but are $\sim 1 \mathrm{~K}$ in WACCMX+DART.
Between 80 and $100 \mathrm{~km}$ altitude, both JAGUAR-DAS and WACCMX+DART indicate Q2DW amplitudes of 1-2 K between 30 and $60^{\circ} \mathrm{S}$. There is also evidence of a small $1-$ $2 \mathrm{~K}$ Q2DW feature in the $\mathrm{NH}$ between approximately 20 and $30^{\circ} \mathrm{N}$ latitude in NAVGEM-HA and JAGUAR-DAS. The quantitative differences in Q2DW amplitudes among the four analyses are likely related to the differences in the structure of the SH summer easterly jet in the upper stratosphere and mesosphere seen in Figs. 3 and 8. Specifically, WACCMX+DART exhibits much stronger easterly flow and less westerly wind shear in the subtropical stratopause region as compared to the other three analyses, and this may result in an environment that does not promote the growth of the Q2DW in the WACCMX+DART system to the extent seen in NAVGEM-HA, MERRA-2, or JAGUAR-DAS. We note that WACCMX+DART, NAVGEM-HA, and JAGUAR-DAS assimilate both MLS and SABER temperatures, whereas MERRA-2 assimilates MLS temperatures. This suggests that differences in the models themselves, rather than the data inputs, may explain the different Q2DW results in Fig. 14.

Next, we examine MLT tidal features in the four analyses. The latitude and altitude dependences of the January 2010 mean diurnal (DW1) and semidiurnal (SW2) migrating solar tidal amplitudes are plotted in Figs. 15 and 16, respectively. Monthly mean DW1 amplitudes in temperature were determined using a bandpass filter for zonal wave number 1 and westward frequencies between 0.9 and $1.1 \mathrm{cpd}$. In the strato- 

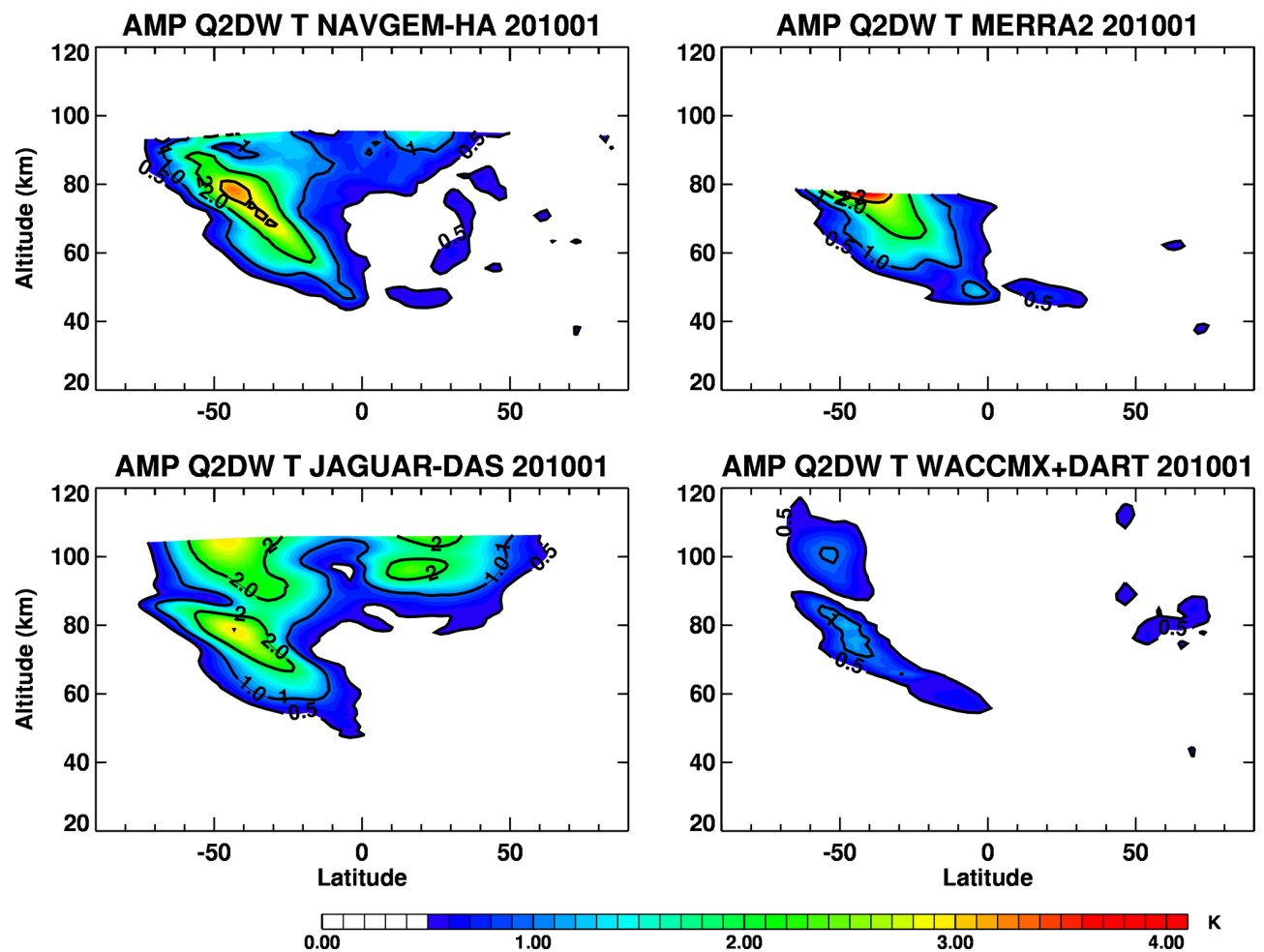

Figure 14. Monthly mean amplitude of the westward zonal wave number 3 quasi-2 d (Q2DW) wave in temperature for January 2010 from NAVGEM-HA, MERRA2, JAGUAR-DAS, and WACCMX+DART.
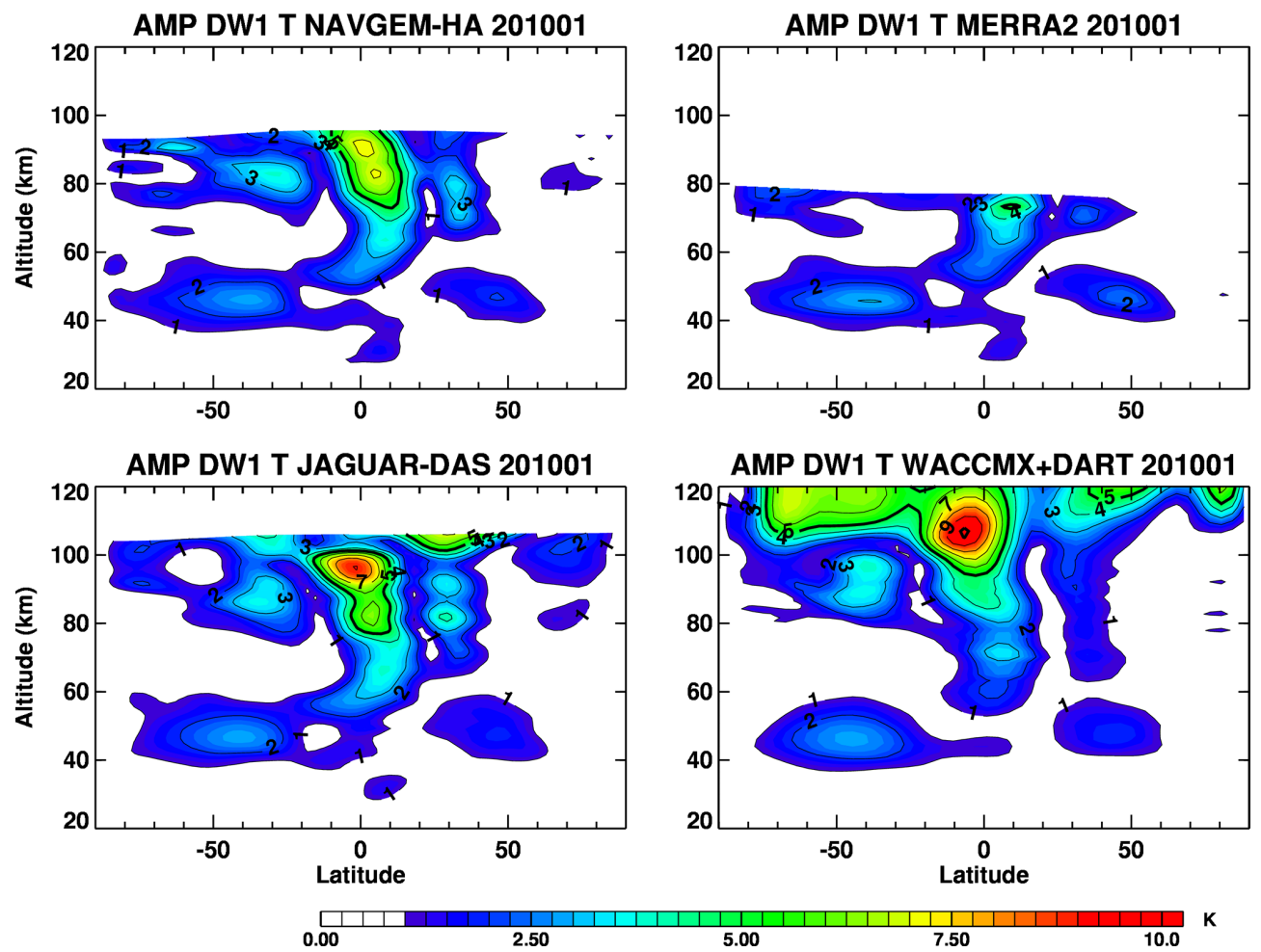

Figure 15. Monthly mean amplitude of the migrating diurnal tide (DW1) in temperature for January 2010 from NAVGEM-HA, MERRA2, JAGUAR-DAS, and WACCMX+DART. 

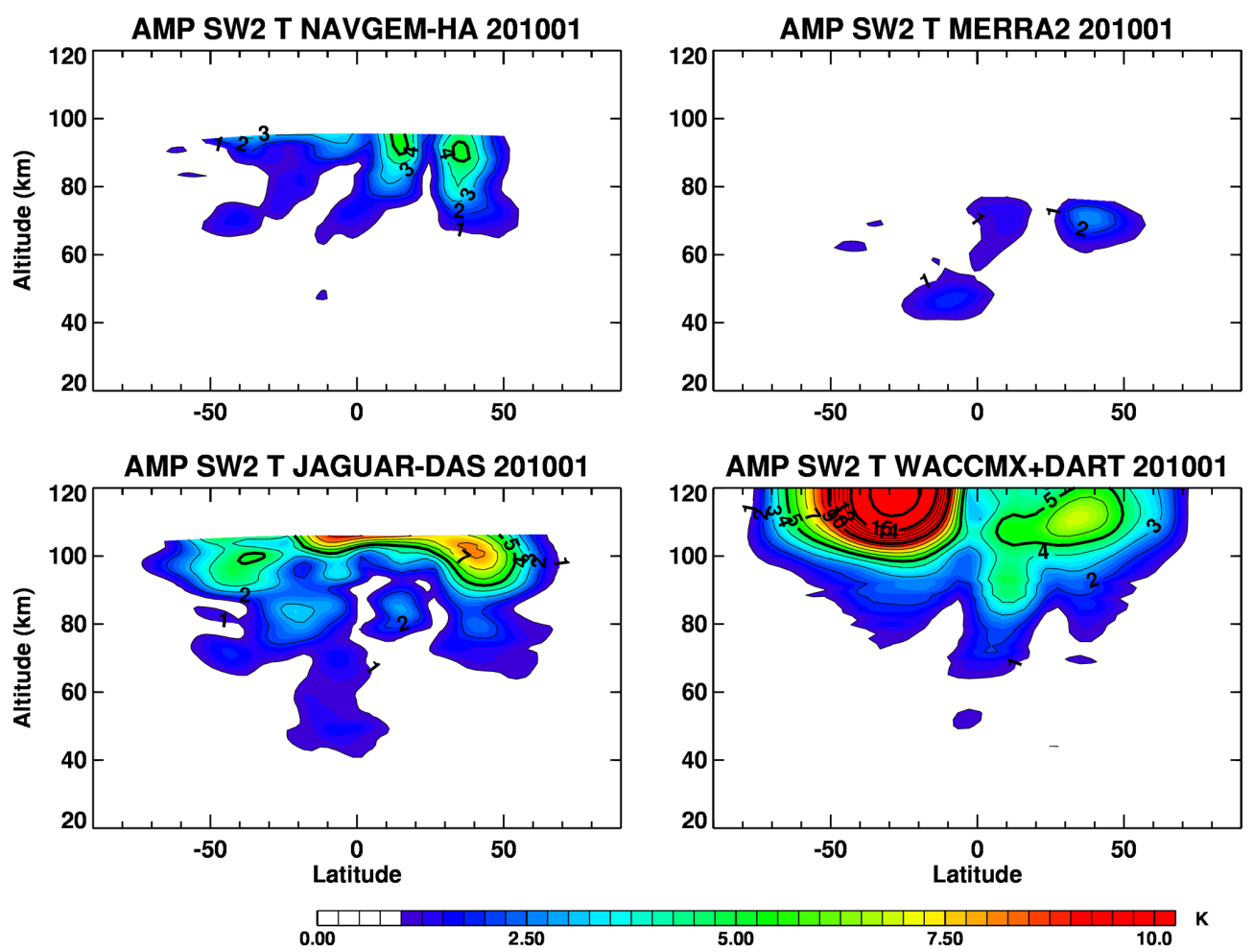

Figure 16. Monthly mean amplitude of the migrating semidiurnal tide (SW2) in temperature for January 2010 from NAVGEM-HA, MERRA2, JAGUAR-DAS, and WACCMX+DART.

sphere, all four analyses show similar DW1 signatures centered on midlatitudes in both hemispheres, similar to those reported by Sakazaki et al. (2012). Between 50 and $80 \mathrm{~km}$ altitude, all four analyses also exhibit similar maxima in DW1 near the Equator with values of $\sim 1-3 \mathrm{~K}$, similar to results published previously (e.g., Forbes and Wu, 2006). Between 80 and $100 \mathrm{~km}$ altitude, NAVGEM-HA, JAGUAR-DAS, and WACCMX+DART exhibit maxima in the equatorial regions, as well as secondary maxima between 30 and $50^{\circ}$ latitude in each hemisphere. The main differences between the DW1 amplitudes among the three analyses extending above $80 \mathrm{~km}$ are the magnitude and vertical location of the equatorial maximum. The NAVGEM-HA DW1 amplitude peaks at $\sim 7 \mathrm{~K}$ at 80-90 km altitude, while in MERRA-2 the peak DW1 amplitude of $\sim 4 \mathrm{~K}$ is near $75 \mathrm{~km}$, in JAGUAR-DAS the peak DW1 amplitude of $\sim 9 \mathrm{~K}$ is located between 95 and $100 \mathrm{~km}$ altitude, and in WACCMX+DART the peak DW1 amplitude of $\sim 10 \mathrm{~K}$ occurs near $110 \mathrm{~km}$ altitude. The range of altitudes for maximum DW1 amplitudes seen in these four analyses agrees with SABER observations (Zhang et al., 2006). For MERRA-2 and possibly NAVGEM-HA, the analysis system upper boundaries are low enough that artificially damping of DW1 may occur. In JAGUAR-DAS, DW1 is dissipated above $\sim 100 \mathrm{~km}$ due to the model diffusion exponentially increasing with height to mimic molecular diffusion. The differences in DW1 structure at/above $100 \mathrm{~km}$ between JAGUAR-
DAS and WACCMX+DART are likely due to the large differences in background zonal mean zonal wind (Fig. 3).

Figure 16 plots January 2010 mean amplitudes of SW2 in temperature obtained using a bandpass filter for zonal wave number 2 and westward frequencies between 1.95 and $2.05 \mathrm{cpd}$ for NAVGEM-HA, MERRA-2, and WACCMX+DART. For JAGUAR-DAS, the bandpass filter cuts off at $2.0 \mathrm{cpd}$, which is the Nyquist frequency for the 6hourly output. Perhaps because of the wide range ( 1 to $6 \mathrm{~h}$ ) of output frequency among the four data sets, the derived amplitudes of the higher-frequency SW2 vary considerably. There are some qualitative similarities in the latitude structure of the SW2 amplitudes between 80 and $100 \mathrm{~km}$ altitude, where NAVGEM-HA, JAGUAR-DAS, and WACCMX+DART all exhibit three peaks near $25^{\circ} \mathrm{S}, 15^{\circ} \mathrm{N}$, and $40^{\circ} \mathrm{N}$ latitude. Near $40^{\circ} \mathrm{N}$ latitude, the peak SW2 amplitude in NAVGEMHA of $\sim 5 \mathrm{~K}$ occurs below $95 \mathrm{~km}$, whereas JAGUAR-DAS and WACCMX+DART indicate peak SW amplitudes ranging from 6 to $8 \mathrm{~K}$ occurring above $100 \mathrm{~km}$ altitude. This suggests that NAVGEM-HA may be missing key features of the SW2 due to its lower model top. Between 100 and $120 \mathrm{~km}$ altitude, WACCMX+DART indicates SW2 amplitudes of $>20 \mathrm{~K}$ from $20^{\circ} \mathrm{S}$ to $40^{\circ} \mathrm{S}$ latitude.

In addition to migrating tides, nonmigrating tides are known to also impact T-I variability. One prominent nonmigrating feature is the eastward-propagating diurnal zonal wave number 3 (DE3) that has been shown to play a role in 

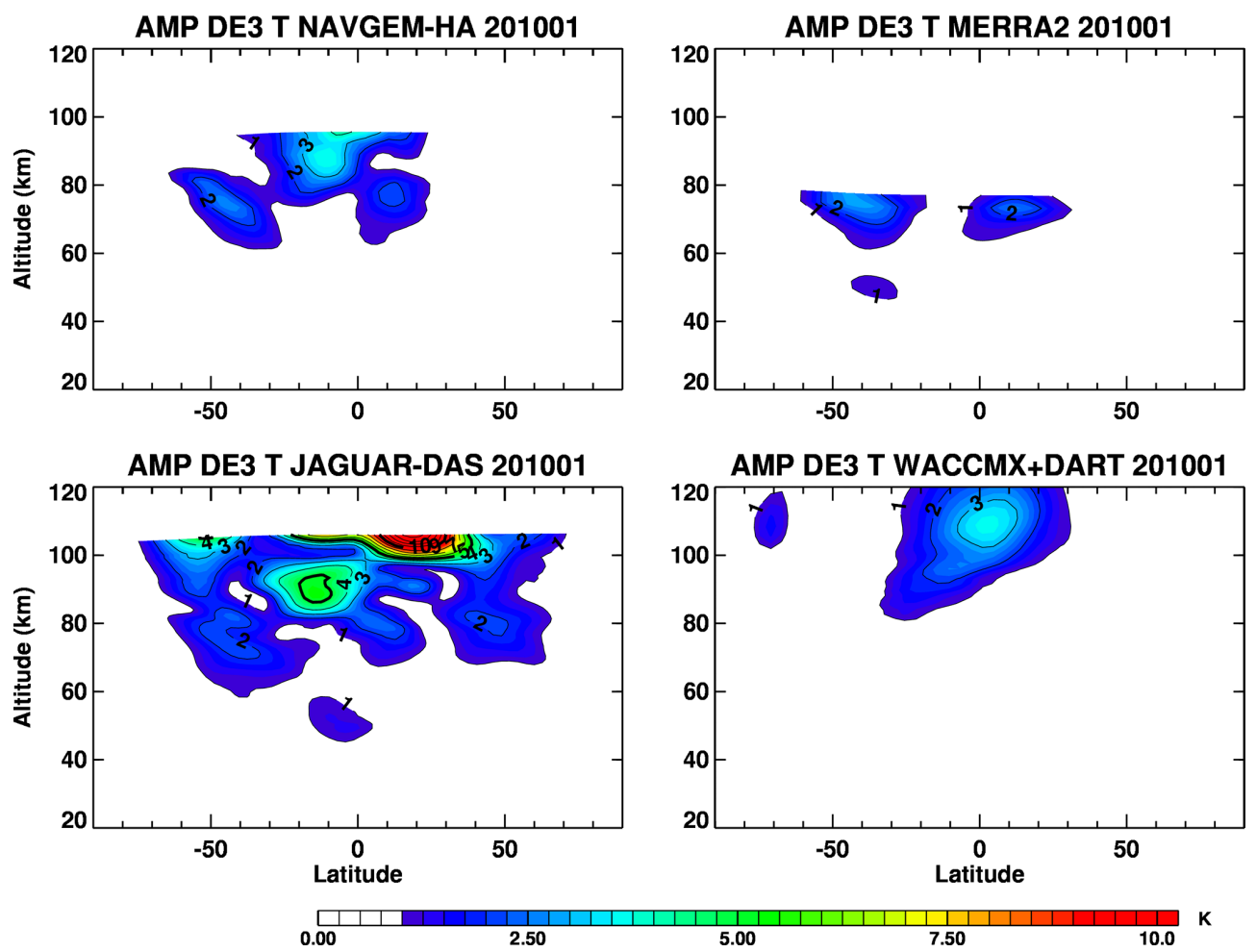

Figure 17. Monthly mean amplitude of the nonmigrating wave 3 diurnal tide (DE3) in temperature for January 2010 from NAVGEM-HA, MERRA2, JAGUAR-DAS, and WACCMX+DART.

establishing pronounced zonal variations in ionospheric total electron content (e.g., Immel et al., 2006; Hagan et al., 2007; McDonald et al., 2018). Variations in DE3 amplitude in relation to SSWs have been noted (Maute et al., 2014), with nonlinear wave-wave interactions within the mesosphere playing an important role in DE3 growth (Lieberman et al., 2015; Sassi et al., 2021). Figure 17 plots the altitude and latitude dependencies of monthly mean DE3 amplitudes for January 2010 obtained using a bandpass filter for zonal wave number 3 and eastward frequencies between 0.9 and $1.1 \mathrm{cpd}$. Overall, DE3 is a feature of the mesosphere and lower thermosphere, although there is some evidence for very small $(\sim 1 \mathrm{~K})$ DE3 amplitudes near the stratopause in MERRA2 (at $\sim 35^{\circ} \mathrm{S}$ ) and JAGUAR-DAS (at $\sim 5^{\circ} \mathrm{S}$ ). Between 60 and $80 \mathrm{~km}$ altitude, the distributions of DE3 amplitudes in NAVGEM-HA, MERRA-2, and JAGUAR-DAS are roughly similar, showing amplitudes of $\sim 2 \mathrm{~K}$ near $40-50^{\circ} \mathrm{S}$ and 10 $20^{\circ} \mathrm{N}$ latitude. JAGUAR-DAS also indicates DE3 amplitudes of $\sim 2 \mathrm{~K}$ in the northern extratropics near $80 \mathrm{~km}$. Above $80 \mathrm{~km}$, NAVGEM-HA and JAGUAR-DAS show peak DE3 amplitudes of 3-4 K in the SH subtropics. The DE3 signature in WACCMX+DART is notably smaller than the other analyses, showing a single peak of $\sim 3 \mathrm{~K}$ near the Equator between 100 and $120 \mathrm{~km}$ altitude.

For purposes of constraining whole atmospheric model experiments, perhaps more important than the monthly mean amplitudes of the tides is the day-to-day tidal variability in the mesosphere and lower thermosphere captured by each of the three high-altitude analyses: NAVGEM-HA, JAGUARDAS, and WACCMX+DART. There is now substantial evidence that circulation changes throughout the stratosphere and mesosphere related to SSWs can modulate the solar migrating tides (Pedatella and Forbes, 2010; Lima et al., 2012; Pedatella and Liu., 2013). Typically, the amplitude of DW1 is seen to decrease in the days leading up to a SSW, followed by a pronounced increase in the amplitude of the SW2 for several days or weeks following the onset of the SSW (e.g., Pedatella and Liu, 2013; Limpasuvan et al., 2016; McCormack et al., 2017). The origins of the tidal modulation by SSWs are still under investigation, but possible causes may include transport-induced changes in the distribution of ozone heating in the equatorial upper stratosphere (Goncharenko et al., 2012; Siddiqui et al., 2019) and variations in zonal mean zonal winds that affect the upward propagation of the tides (McLandress, 2002; Sassi et al., 2013).

Figures 18-20 show the time variations in the amplitudes of diurnal wave number 1 , semidiurnal wave number 2 , and diurnal wave number 3 in temperature at $90 \mathrm{~km}$ as a function of latitude throughout the course of the 2010 SSW and subsequent polar vortex recovery phase. These time variations are obtained using the FFT and S-transform methods described in Sect. 2. We note that the S-transform method by itself does not distinguish between eastward- and westwardpropagating features. However, based on examination of in- 


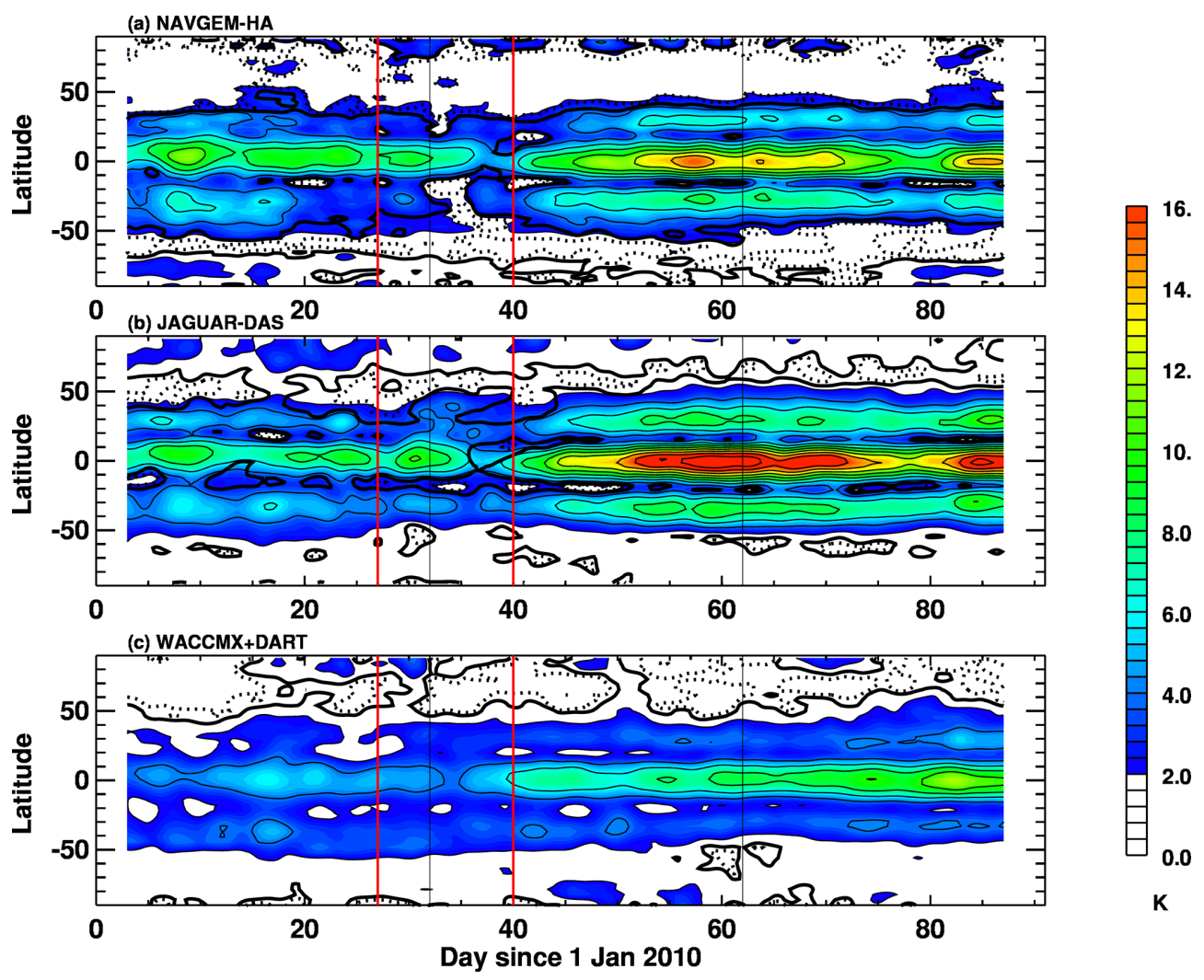

Figure 18. Latitude-time sections of the amplitude in migrating diurnal wave 1 (DW1) temperature variations at $90 \mathrm{~km}$ altitude from (a) NAVGEM-HA, (b) JAGUAR-DAS, and (c) WACCMX+DART for January-February-March 2010. Thin, solid black contours are drawn every $2 \mathrm{~K}$. Bold dashed and solid black contours indicate regions where results from wavelet analysis exceed $90 \%$ and $95 \%$ confidence levels. Vertical red lines in each panel denote 27 January and 9 February, as described in the text. Vertical black lines in each panel denote 1 February and 1 March.

dividual 2DFFT spectra (not shown), we find that the dominant spectral features associated with diurnal wave 1, semidiurnal wave 2, and diurnal wave 3 in the temperature fields at this level correspond to DW1, SW2, and DE3, respectively. To avoid edge effects commonly associated with wavelet methods, results for the first and last $3 \mathrm{~d}$ in the time period are not plotted in Figs. 18-20.

The latitude-time variations of DW1 temperature amplitudes at $90 \mathrm{~km}$ altitude from 1 January to 31 March 2010 from the three high-altitude analyses in Fig. 18 all show qualitatively consistent behavior, most notably a reduction in equatorial amplitudes in early February and a broad increase in amplitudes throughout the topics and subtropics approaching equinox conditions in March, when climatological DW1 temperature amplitudes are largest. During the January-March 2010 period, peak WACCMX+DART diurnal wave 1 amplitudes are roughly half as large as values in NAVGEM-HA and JAGUAR-DAS. We note that the DW1 results from all three analyses plotted in Fig. 19 exceed the $95 \%$ confidence level at most latitudes.

For SW2 (Fig. 19), the peak WACCMX+DART amplitudes at $90 \mathrm{~km}$ are also generally less than peak values in the
NAVGEM-HA or JAGUAR-DAS results. However, we note that in early February, all three high-altitude data sets indicate similar increases in the semidiurnal wave 2 amplitude of $\sim 8-10 \mathrm{~K}$ near $10^{\circ} \mathrm{N}$ latitude that exceed the $95 \%$ confidence levels. The NAVGEM-HA results show amplitudes of $\sim 8 \mathrm{~K}$ in SW2 near $40-50^{\circ} \mathrm{N}$ throughout February that are not present in WACCMX+DART or JAGUAR-DAS results. In addition, the JAGUAR-DAS results indicate numerous short-lived large amplitude features at high latitudes not seen in NAVGEM-HA or WACCMX+DART. Given the 6-hourly sampling of JAGUAR-DAS, these high latitude maxima may be an artifact produced by aliasing of higher-frequency variations since the $2.0 \mathrm{cpd}$ semidiurnal frequency corresponds to the Nyquist limit for JAGUAR-DAS output.

The time variations in DE3 at $90 \mathrm{~km}$ (Fig. 20) show some qualitative similarities among the three analyses, most notably a 30-40 d modulation of peak amplitudes throughout the $50^{\circ} \mathrm{S}-50^{\circ} \mathrm{N}$ latitude region that exceeds the $95 \%$ confidence estimate. Given the relationship of the nonmigrating DE3 tide to convective sources (e.g., Forbes et al., 2008), these low-frequency variations could be a manifestation of intra-seasonal modes such as the Madden-Julian oscillation, 

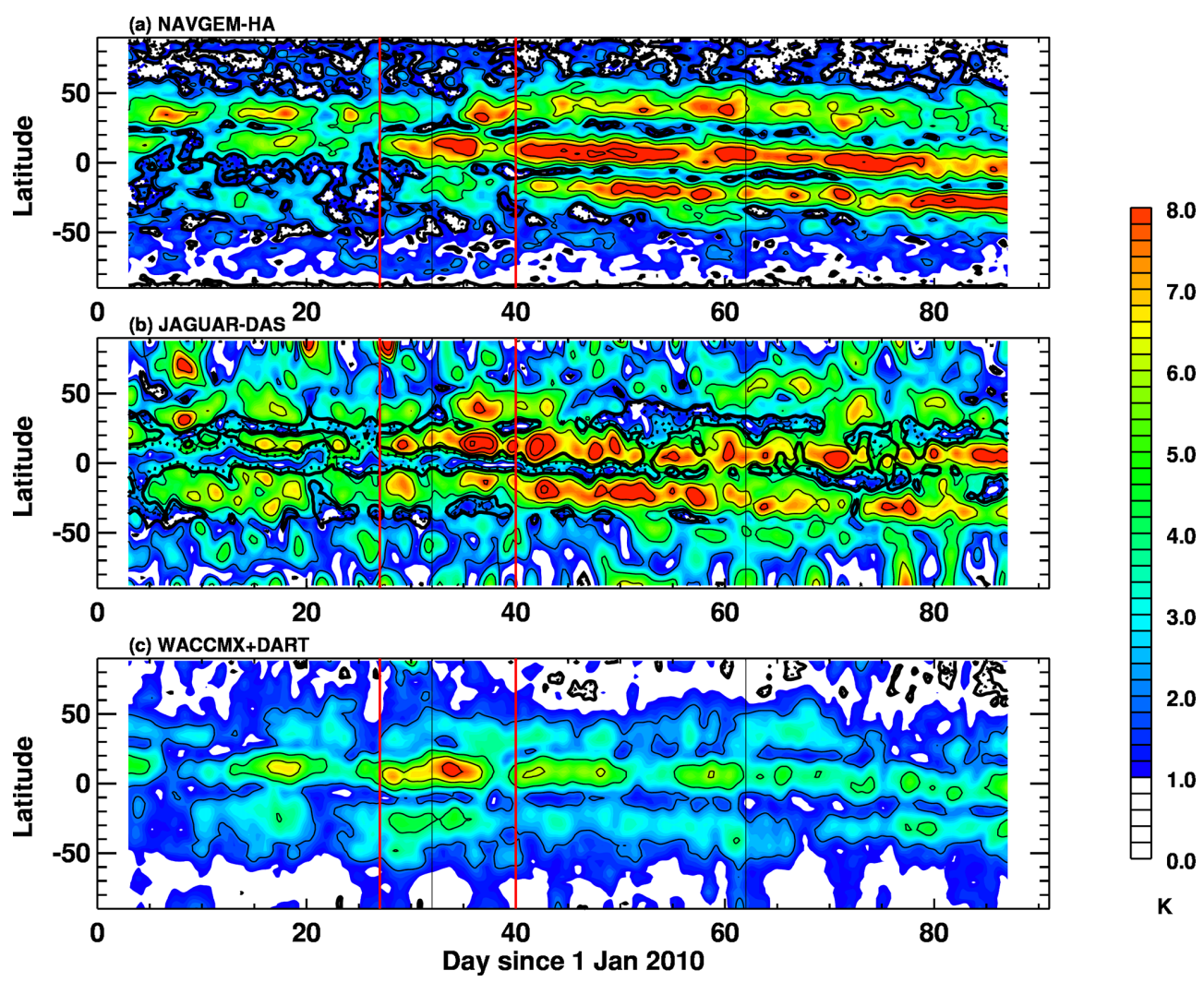

Figure 19. As in Fig. 18 but for the migrating semidiurnal wave 2 (SW2).

which has been shown to have a signature in the T-I system on timescales longer than $30 \mathrm{~d}$ (e.g., Sassi at al., 2019). As with the diurnal wave 1 and semidiurnal wave 2 results, the amplitudes of the diurnal wave 3 temperature variations at $90 \mathrm{~km}$ throughout the January-March 2010 period in Fig. 20 derived from WACCMX+DART are generally a factor of 2 smaller than amplitudes derived from the NAVGEM-HA or JAGUAR-DAS temperature data sets.

To summarize the differences among NAVGEM-HA, JAGUAR-DAS, and WACCMX+DART associated with each of the zonal wave-number-frequency pairs plotted in Figs. 18-20 prior to the major SSW of 2010, Fig. 21 plots latitude distributions of the mean amplitude and \pm 1 standard deviation in the temperature amplitudes for the period from 27 January to 9 February derived from the S-transform analysis. For diurnal wave 1 (Fig. 21a), all three analyses show the largest amplitudes near the Equator; NAVGEMHA and JAGUAR-DAS peak values are both $\sim 7 \mathrm{~K}$, while the WACCMX+DART peak value is $\sim 4 \mathrm{~K}$. For semidiurnal wave 2 (Fig. 21b), all three analyses exhibit similar peak values from 5 to $15^{\circ} \mathrm{N}$ with maximum amplitudes of $6-8 \mathrm{~K}$. Between 30 and $40^{\circ} \mathrm{N}$, both NAVGEM-HA and JAGUARDAS show a secondary peak in SW2 amplitude of $\sim 5 \mathrm{~K}$, while corresponding WACCMX+DART values are $\sim 3 \mathrm{~K}$. In addition, JAGUAR-DAS results show a secondary peak in SW2 amplitude between 10 and $20^{\circ} \mathrm{S}$ latitude; this peak is smaller in amplitude in NAVGEM-HA and is shifted poleward (to $\sim 20-40^{\circ} \mathrm{S}$ ) in WACCMX+DART. Results from JAGUAR-DAS show larger SW2 amplitudes at high latitudes $\left(80-90^{\circ} \mathrm{S}\right.$ and $\left.60-90^{\circ} \mathrm{N}\right)$ than in either NAVGEM-HA or WACCMX+DART. For diurnal wave 3 (Fig. 21c), both NAVGEM-HA and JAGUAR-DAS indicate peak DE3 values of $\sim 4 \mathrm{~K}$ between the Equator and $20^{\circ} \mathrm{S}$ latitude, while WACCMX+DART shows no indication of a distinct DE3 signal.

Overall, the results in Fig. 21 suggest that while there is general qualitative agreement in the latitude structure of DW1, SW2, and DE3 among the three meteorological analyses extending to $90 \mathrm{~km}$ altitude, there are important quantitative differences. These differences are likely related to the details of each assimilation system regarding the type of observations being assimilated, the type of atmospheric model employed, and differences in the temporal and spatial resolutions of each system. For example, it is possible that the 6hourly output of JAGUAR-DAS, which is at the Nyquist frequency for SW2, may result in some aliasing of other signals; this could potentially explain some of the high-latitude SW2 amplitudes seen in JAGUAR-DAS (Fig. 21b) but not in either NAVGEM-HA or WACCMX+DART. We emphasize that the results in Fig. 21 are for a single altitude region $(90 \mathrm{~km})$. The comparisons would likely be quite different at higher altitudes where, for example, there is evidence of larger 


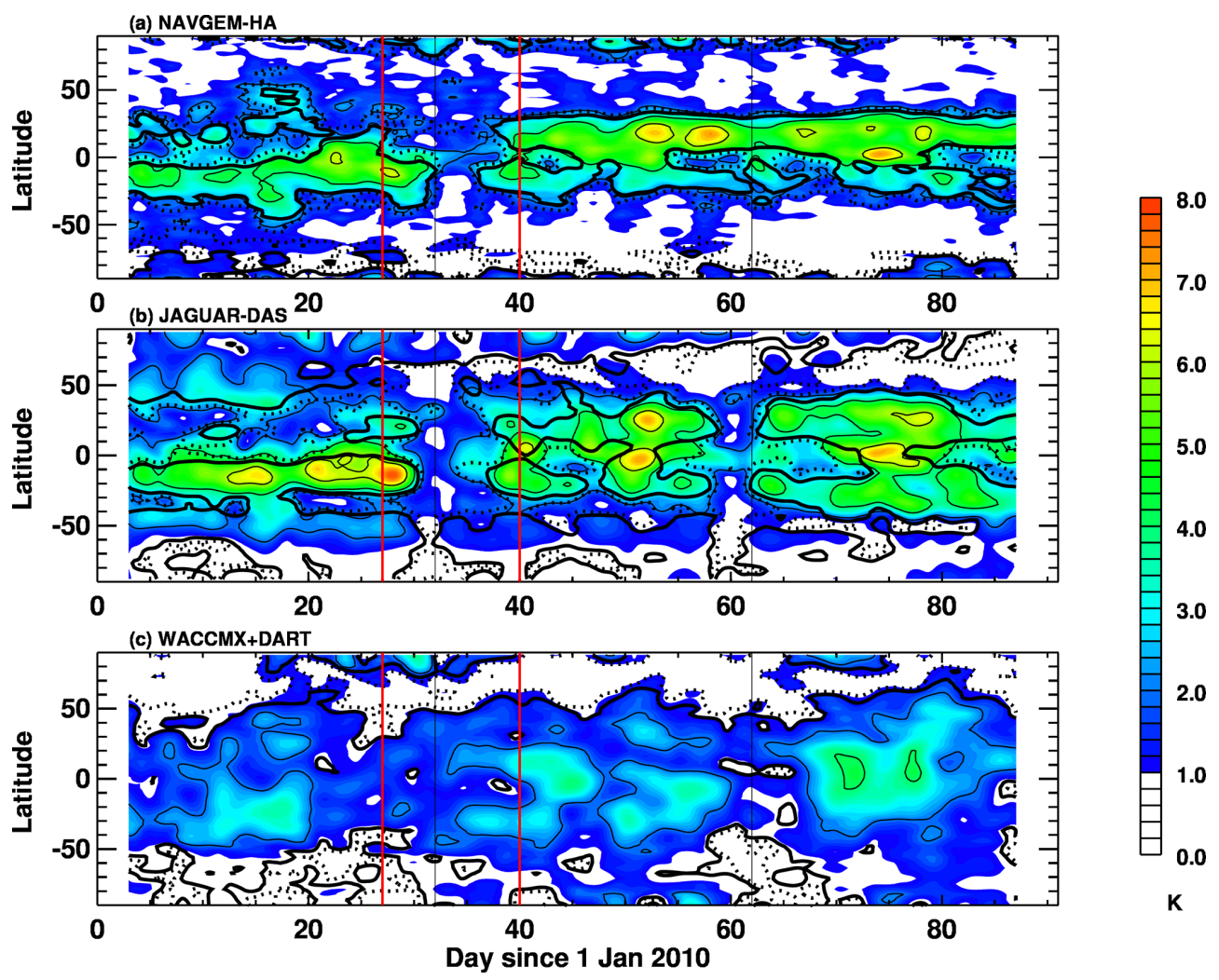

Figure 20. As in Fig. 18 but for the nonmigrating diurnal wave 3 (DE3).

DW1 amplitudes during January 2010 in WACCMX+DART than in either NAVGEM-HA or JAGUAR-DAS. Further intercomparison of results among these (and possibly other) high-altitude meteorological analyses are needed to expand upon the initial results presented here. Nevertheless, the differences noted here in Figs. 18-21 indicate that the choice of high-altitude meteorological data set to constrain dayto-day meteorological variations in whole atmosphere models related to diurnal and semidiurnal tides (either migrating or nonmigrating) may impact the results, particularly in the equatorial regions. Thus, we advise users of these analyses to compare results to observations and/or other analyses to increase confidence. Further investigations in which these types of differences are incorporated into constrained or "nudged" whole atmosphere model simulations as a source of uncertainty may be helpful to better quantify the impact of meteorological activity on day-to-day variations in the T-I system.

\section{Summary and discussion}

Based on the results of this intercomparison among four analysis systems that assimilate middle atmospheric satellite observations, we find that there is overall good agreement in the latitude, altitude, and time behavior of the zonal mean temperature and zonal winds up to approximately $50 \mathrm{~km}$ altitude during the December 2009 to March 2010 period. This finding is consistent with the results presented in Harvey et al. (2021), which examined 10 reanalysis data sets but only 1 (MERRA-2) that extended above the stratopause and assimilated middle atmospheric temperature observations (from MLS). Also consistent with Harvey et al. (2021), we find that significant differences among the four analyses begin to emerge above $50 \mathrm{~km}$ altitude at low latitudes. The present intercomparison among the NAVGEM-HA, JAGUAR-DAS, and WACCMX+DART analyses shows how large interanalysis differences can extend above $80 \mathrm{~km}$ altitude. As summarized in Fig. 10, the largest zonal mean temperature differences among the analyses, ranging from 10 to $15 \mathrm{~K}$, are found near $90 \mathrm{~km}$. However, we find that the largest zonal mean zonal wind differences are found not at the highest altitudes but near $50 \mathrm{~km}$ altitude at the Equator (Fig. 11). This latter result highlights the fact that these middle atmosphere analyses do not currently produce a consistent description of key climatological features such as the SAO in zonal mean zonal wind near the stratopause (Kawatani et al., 2020). A recent study by Hindley et al. (2020) highlights the importance of the SAO in modulating gravity wave momentum flux into the mesosphere and lower thermosphere. Assuming the time period evaluated here is representative of broader behavior, this disagreement in the time behavior of the zonal mean zonal winds in the tropical mesosphere and lower thermo- 

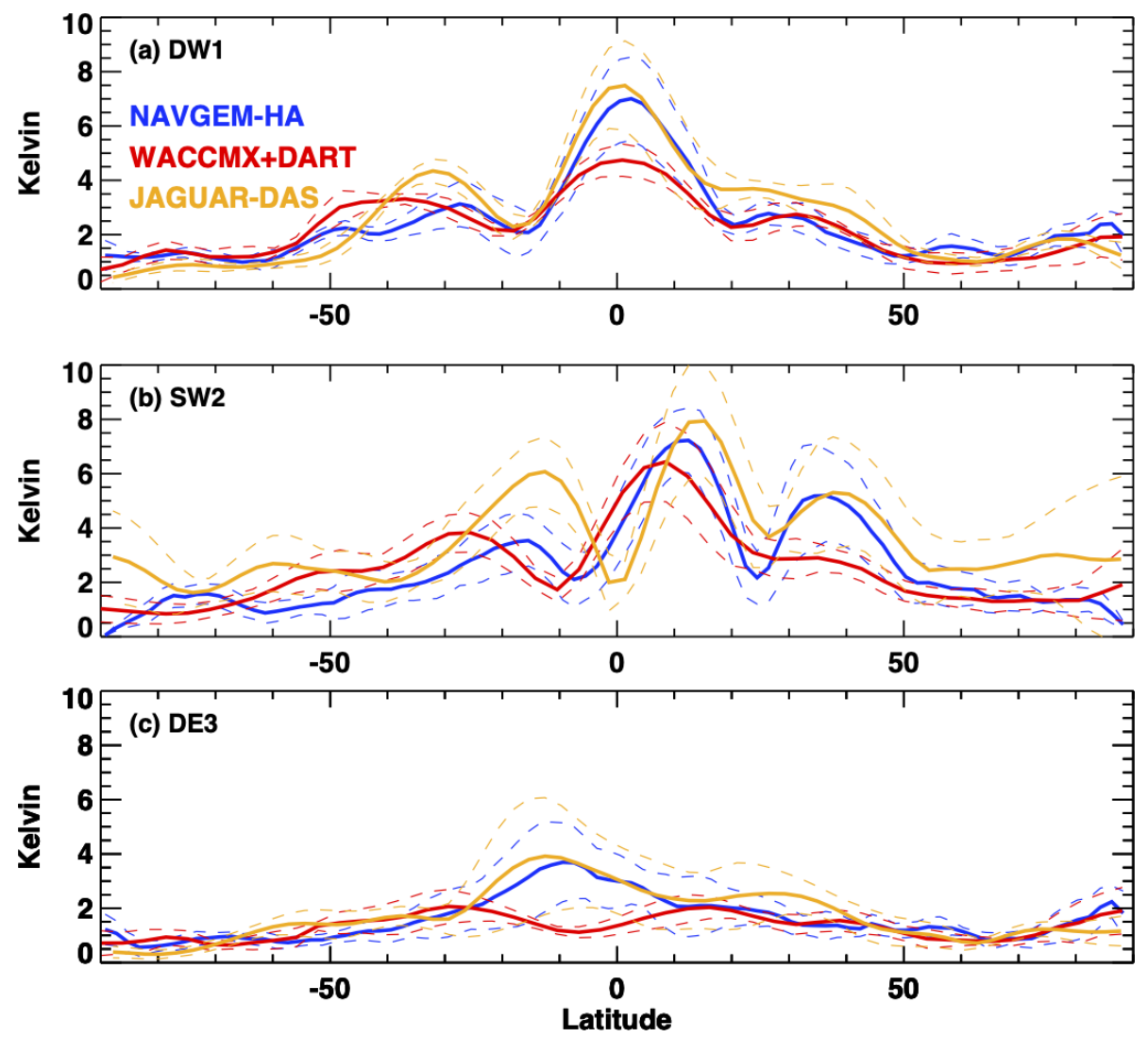

Figure 21. Latitude dependence of the mean amplitude and \pm 1 standard deviation values for (a) migrating diurnal wave 1 (DW1), (b) migrating semidiurnal wave 2 (SW2), and (c) nonmigrating diurnal wave 3 (DE3) at $90 \mathrm{~km}$ altitude obtained from NAVGEM-HA, WACCMX+DART, and JAGUAR-DAS from 27 January to 9 February from Figs. 18-20.

sphere (Fig. 8) among the four analyses should be remedied in order to improve confidence in the use of these analyses for studies of MLT dynamics, as well as for input to whole atmosphere models to constrain lower atmospheric meteorological variability.

Intercomparison of the PW and tidal features examined here finds that the representations of the Q5DW and Q2DW in the 2009-2010 NH winter period are fairly consistent among these four analyses. Important differences emerge when comparing the latitude, altitude, and time behavior of temperature variations related to the DW1, SW2, and DE3 tides above $80 \mathrm{~km}$ altitude. In particular, WACCMX+DART tidal amplitudes are consistently smaller than corresponding amplitudes in the NAVGEM-HA and JAGUAR-DAS data sets over the 2009-2010 NH winter period evaluated here. This is related to additional second-order divergence damping that was included in the version of WACCMX+DART used for the present study and that has subsequently been removed, leading to increased tidal amplitudes in WACCMX+DART (Pedatella et al., 2020). As Fig. 21 shows, there can be as much as a factor of 2 difference in the temperature variance associated with equatorial DW1 among the analyses at $90 \mathrm{~km}$ altitude over the January-
March 2010 period. Further study is needed to examine possible causes of the disagreement among the analyses, focusing both on the different types of middle atmospheric observations being assimilated (e.g., temperature profiles only vs. temperatures and constituents), the assimilation methods being used (e.g., 4DVAR vs. ensemble-based, retrieval vs. radiance assimilation), and the details of the model physics (e.g., gravity wave drag, radiative heating parameterizations) being employed by each system.

It is important to note that this initial intercomparison is not meant to be the final word on the characteristics of these analyses but rather a starting point. Given the extensive effort and computational resources involved in producing these data sets, a more thorough comparison over many years is beyond the scope of the present study. We also note that the systems producing these analyses are constantly evolving in order to improve both research and operational capabilities for specifying middle atmosphere conditions. Ultimately, more extensive intercomparisons that examine both seasonal and interannual variability of key middle atmospheric features (e.g., upward-propagating waves and tides, SSWs, and mesospheric coolings) over many years using the most recent version of the data available will be needed in the future. The 
aim of this study is to provide some initial insight on where efforts to improve these systems could be most useful. One area for improvement highlighted in this study is in the representation of the equatorial SAO in the upper stratosphere and lower mesosphere. This effort would be facilitated in the future by ensuring that these high-altitude meteorological analysis systems routinely save fields quantifying the parameterized sub-grid-scale gravity wave drag.

To further pursue improvements in these middle atmospheric meteorological systems, a follow-on validation study is planned in which independent (i.e., not assimilated) satellite- and ground-based middle atmosphere observations are used to evaluate each of these data sets. Some examples of independent ground-based observations for validation of middle atmospheric analyses include mesospheric horizontal wind profiles derived from meteor radars (e.g., Stober et al., 2020) and temperature profiles from lidar (e.g., Marlton et al., 2021). Some examples of independent satellitebased observations that have been used for validation include wind observations from the TIMED Doppler Interferometer (TIDI; Dhadly et al., 2018), and constituent profiles from the Solar Occultation for Ice Experiment (SOFIE; Siskind et al., 2019). A future validation study would greatly benefit from interaction with existing groups such as the Network for the Detection of Atmospheric Composition Change (NDAAC; Marlton et al., 2021) and the Atmospheric dynamics Research Infrastructure in Europe (ARISE; Blanc et al., 2018). Lastly, we would also encourage participation from other research centers producing middle atmosphere analyses in any follow-on studies motivated by the present work under the auspices of the SPARC Data Assimilation Working Group or similar organizations.

Data availability. WACCMX+DART wind and temperature output for December 2009 to March 2010 is publicly available at https://doi.org/10.5065/d88c-y005 (Pedatella, 2021). The data from JAGUAR-DAS are available on request. NAVGEM-HA analyses for the 2009-2010 winter period are available at https:// map.nrl.navy.mil/map/pub/nrl/navgem/iap/ (last access: 16 November 2021). MERRA-2 analysis fields are available from the NASA Goddard Earth Sciences (GES) Data and Information Services Center (DISC), with this study's model level MERRA-2 fields available at https://disc.gsfc.nasa.gov/datasets/M2I3NVASM_5.12. 4/summary (last access: 16 November 2021). Post-processed (zonal mean) model data from all four modeling systems used to reproduce figures that appear in this work can be accessed via https://doi.org/10.5281/zenodo.5567401 (McCormack et al., 2021).

Supplement. The supplement related to this article is available online at: https://doi.org/10.5194/acp-21-17577-2021-supplement.

Author contributions. JPM and VLH conceived this study, carried out the data analyses, and wrote the majority of the paper. CER as- sisted in the scientific interpretation of the results and writing. NP, DK, KS, LC, and SW provided key data sets and contributed to the data description and interpretation of the results. FS and LAH provided content for figures and assisted in data analysis and interpretation of the results.

Competing interests. The authors declare that they have no conflict of interest.

Disclaimer. Publisher's note: Copernicus Publications remains neutral with regard to jurisdictional claims in published maps and institutional affiliations.

Acknowledgements. We thank the two reviewers whose comments and questions improved the quality of this manuscript. John P. McCormack and Fabrizio Sassi acknowledge support from the NASA DRIVE program and the Naval Research Laboratory Base Program. V. Lynn Harvey acknowledges support from the NASA Heliophysics Supporting Research, Guest Investigator, and DRIVE programs. Cora E. Randall, Nicholas Pedatella, and Laura A. Holt acknowledge support from the NASA DRIVE program. Production of NAVGEM-HA data was supported by a grant of computer time from the Department of Defense High Performance Computing Modernization program. Lawrence Coy was supported by the NASA Modeling, Analysis, and Prediction program. Resources for production of MERRA-2 were provided by the NASA High-End Computing (HEC) program through the NASA Center for Climate Simulation (NCCS) at Goddard Space Flight Center. Kaoru Sato, Dai Koshin, and Shingo Watanabe are supported by the Japan Science and Technology Agency Core Research for Evolutional Science and Technology (grant no. JPMJCR1663).

Financial support. This research has been supported by the National Aeronautics and Space Administration (grant nos. 80NSSC20K0628, 80NSSC18K1046, 80NSSC190262, and 80NSSC19K0834) and the National Center for Atmospheric Research, which is a major facility sponsored by the US National Science Foundation under Cooperative Agreement 1852977.

Review statement. This paper was edited by Rolf Müller and reviewed by Young-Ha Kim and one anonymous referee.

\section{References}

Anderson, J. L., Hoar, T., Raeder, K., Liu, H., Collins, N., Torn, R., and Arellano, A. F.: The Data Assimilation Research Testbed: A community data assimilation facility, B. Am. Meteorol. Soc., 90, 1283-1296, https://doi.org/10.1175/2009BAMS2618.1, 2009.

Becker, E. and Vadas, S. L.: Secondary gravity waves in the winter mesosphere: Results from a high-resolution global circulation model, J. Geophys. Res., 123, 2605-2627, https://doi.org/10.1002/2017JD027460, 2018. 
Beres, J. H., Garcia, R. R., Boville, B. A., and Sassi, F.: Implementation of a gravity wave source spectrum parameterization dependent on the properties of convection in the Whole Atmosphere Community Climate Model (WACCM), J. Geophys. Res., 110, D10108, https://doi.org/10.1029/2004JD005504, 2005.

Bosilovich, M., Akella, S., Coy, L., Cullather, R., Draper, C., Gelaro, R., Kovach, R., Liu, Q., Molod, A., Norris, P., Wargan, K., Chao, W., Reichle, R., Takacs, L., Vikhliaev, Y., Bloom, S., Collow, A., Firth, S., Labow, G., Partyka, G., Pawson, S., Reale, O., Schubert, S. D., and Suarez, M.: MERRA-2: Initial evaluation of the climate, NASA Tech. Report Series on Global Modeling and Data Assimilation, NASA/TM-2015-104606, Vol. 43, NASA Goddard Space Flight Center, Greenbelt, Maryland, 2015.

Blanc, E., Ceranna, L., Hauchecorne, A., Charlton-Perez, A., Marchetti, E., Evers, L. G., Kvaerna, T., Lastovicka, J., Eliasson, L., Crosby, N. B., Blanc-Benon, P., Le Pichon, A., Brachet, N., Pilger, C., Keckhut, P., Assink, J. D., Smets, P. S. M., Lee, C. F., Kero, J., Sindelarova, T., Kämpfer, N., Rüfenacht, R., Farges, T., Millet, C., Näsholm, S. P., Gibbons, S. J., Espy, P. J., Hibbins, R. E., Heinrich, P., Ripepe, M., Khaykin, S., Mze, N., and Chum, J.: Toward an improved representation of middle atmospheric dynamics thanks to the ARISE Project, Surv. Geophys., 39, 171-225, https://doi.org/10.1007/s10712-017-9444-0, 2018.

Burks, D. and Leovy, C.: Planetary waves near the mesospheric easterly jet, Geophys. Res. Lett., 13, 193-196, https://doi.org/10.1029/GL013i003p00193, 1986.

Butler, A. H., Sjoberg, J. P., Seidel, D. J., and Rosenlof, K. H.: A sudden stratospheric warming compendium, Earth Syst. Sci. Data, 9, 63-76, https://doi.org/10.5194/essd-9-63-2017, 2017.

Chandran, A., Garcia, R. R., Collins, R. L., and Chang, L. C.: Secondary planetary waves in the middle and upper atmosphere following the stratospheric sudden warming event of January 2012, Geophys. Res. Lett., 40, 1861-1867, https://doi.org/10.1002/grl.50373, 2013.

Chang, L. C., Palo, S. E., and Liu, H.-L.: Short-term variability in the migrating diurnal tide caused by interactions with the quasi 2-day wave, J. Geophys. Res., 116, D12112, https://doi.org/10.1029/2010JD014996, 2011.

Chang, L. C., Yue, J., Wang, W., Wu, Q., and Meier, R. R.: Quasi two-day wave-related variability in the background dynamics and composition of the mesosphere/thermosphere, and the ionosphere, J. Geophys. Res.-Space, 119, 4786-4804, https://doi.org/10.1002/2014JA019936, 2014.

Chau, J. L., Fejer, B. G., and Goncharenko, L. P.: Quiet variability of equatorial ExB drifts during a sudden stratospheric warming event, Geophys. Res. Lett., 36, L05101, https://doi.org/10.1029/2008GL036785, 2009.

Coy, L.: A possible 2-day oscillation near the tropical stratopause, J. Atmos. Sci., 36, 1615-1618, https://doi.org/10.1175/15200469(1979)036<1615:APDONT>2.0.CO;2, 1979.

Coy, L., Wargan, K., Molod, A. M., McCarty, W. R., and Pawson, S.: Structure and dynamics of the quasibiennial oscillation in MERRA-2, J. Climate, 29, 5339-5354, https://doi.org/10.1175/JCLI-D-15-0809.1, 2016.

Danabasoglu, G., Lamarque, J.-F., Bacmeister, J., Bailey, D. A., DuVivier, A. K., Edwards, J., Emmons, L. K., Fasullo, J., Garcia, R., Gettelman, A., Hannay, C., Holland, M. M., Large, W. G., Lauritzen, P. H., Lawrence, D. M., Lenaerts, J. T. M., Lindsay, K., Lipscomb, W. H., Mills, M. J., Neale, R., Ole- son, K. W., Otto-Bliesner, B., Phillips, A. S., Sacks, W., Tilmes, S., van Kampenhout, L., Vertenstein, M., Bertini, A., Dennis, J., Deser, C., Fischer, C., Fox-Kemper, B., Kay, J. E., Kinnison, D., Kushner, P. J., Larson, V. E., Long, M. C., Mickelson, S., Moore, J. K., Nienhouse, E., Polvani, L., Rasch, P. J., and Strand, W. G.: The Community Earth System Model Version 2 (CESM2), J. Adv. Model. Earth Sys., 12, e2019MS001916, https://doi.org/10.1029/2019MS001916, 2020.

Dee, D. P., Uppala, S. M., Simmons, A. J., Berrisford, P., Poli, P., Kobayashi, S., Andrae, U., Balmaseda, M. A., Balsamo, G., Bauer, P., Bechtold, P., Beljaars, A. C. M., van de Berg, L., Bidlot, J., Bormann, N., Delsol, C., Dragani, R., Fuentes, M., Geer, A. J., Haimberger, L., Healy, S. B., Hersbach, H., Hólm, E. V., Isaksen, L., Kållberg, P., Köhler, M., Matricardi, M., McNally, A. P., Monge-Sanz, B. M., Morcrette, J.-J., Park, B.-K., Peubey, C., de Rosnay, P., Tavolato, C., Thépaut, J.-N., and Vitart, F.: The ERA-Interim reanalysis: configuration and performance of the data assimilation system, Q. J. Roy. Meteor. Soc., 137, 553-597, https://doi.org/10.1002/qj.828, 2011.

de Wit, R. J., Hibbins, R. E., Espy, P. J., and Hennum, E. A.: Coupling in the middle atmosphere related to the 2013 major sudden stratospheric warming, Ann. Geophys., 33, 309-319, https://doi.org/10.5194/angeo-33-309-2015, 2015.

Dhadly, M. S., Emmert, J. T., Drob, D. P., McCormack, J. P., and Niciejewski, R.: Short-term and interannual variations of migrating diurnal and semidiurnal tides in the mesosphere and lower thermosphere, J. Geophys. Res., 123, 7106-7123, https://doi.org/10.1029/2018JA025748, 2018.

Eckermann, S. D.: Explicitly stochastic parameterization of nonorographic gravity wave drag, J. Atmos. Sci., 68, 1749-1765, https://doi.org/10.1175/2011JAS3684.1, 2011.

Eckermann, S. D., Ma, J., Hoppel, K. W., Kuhl, D. D., Allen, D. R., Doyle, J. A., Viner, K. C., Ruston, B. C., Baker, N. L., Swadley, S. D., Whitcomb, T. R., Reynolds, C. A., Xu, L., Kaifler, N., Kaifler, B., Reid, I. M., Murphy, D. J., and Love, P. T.: High-Altitude (0-100 km) Global Atmospheric Reanalysis System: Description and Application to the 2014 Austral Winter of the Deep Propagating Gravity Wave Experiment (DEEPWAVE), Mon. Weather Rev., 146, 2639-2666, https://doi.org/10.1175/MWRD-17-0386.1, 2018.

Ern, M., Preusse, P., Kalisch, S., Kaufmann, M., and Riese, M.: Role of gravity waves in the forcing of quasi two-day waves in the mesosphere: An observational study, J. Geophys. Res.-Atmos., 118, 3467-3485, https://doi.org/10.1029/2012JD018208, 2013.

Eswaraiah, S., Kim, Y. H., Liu, H, Venkat Ratnam, M., and Lee, J.: Do minor sudden stratospheric warmings in the Southern Hemisphere (SH) impact coupling between stratosphere and mesosphere-lower thermosphere (MLT) like major warmings?, Earth Planets Space, 69, 119, https://doi.org/10.1186/s40623017-0704-5, 2017.

Forbes, J. M. and Wu, D.: Solar tides as revealed by measurements of mesosphere temperature by the MLS experiment on UARS, J. Atmos. Sci., 63, 1776-1797, https://doi.org/10.1175/JAS3724.1, 2006.

Forbes, J. M. and Zhang, X.: The quasi-6 day wave and its interactions with solar tides, J. Geophys. Res.-Space, 122, 4764-4776, https://doi.org/10.1002/2017JA023954, 2017.

Forbes, J. M., Zhang, X., Palo, S., Russell III, J. M., Mertens, C. J., and Mlynczak, M.: Tidal variability in the iono- 
spheric dynamo region, J. Geophys. Res., 113, A02310, https://doi.org/10.1029/2007JA012737, 2008.

France, J. A., Randall, C. E., Lieberman, R. S., Harvey, V. L., Eckermann, S. D., Siskind, D. E., Lumpe, J. D., Bailey, S. M., Carstens, J. N., and Russell III, J. M.: Local and remote planetary wave effects on polar mesospheric clouds in the Northern Hemisphere in 2014, J. Geophys. Res.-Atmos., 123, 5149-5162, https://doi.org/10.1029/2017JD028224, 2018.

Fritts, D. C. and Alexander, M. J.: Gravity wave dynamics and effects in the middle atmosphere, Rev. Geophys., 41, 1003, https://doi.org/10.1029/2001RG000106, 2003.

Fujiwara, M., Wright, J. S., Manney, G. L., Gray, L. J., Anstey, J., Birner, T., Davis, S., Gerber, E. P., Harvey, V. L., Hegglin, M. I., Homeyer, C. R., Knox, J. A., Krüger, K., Lambert, A., Long, C. S., Martineau, P., Molod, A., Monge-Sanz, B. M., Santee, M. L., Tegtmeier, S., Chabrillat, S., Tan, D. G. H., Jackson, D. R., Polavarapu, S., Compo, G. P., Dragani, R., Ebisuzaki, W., Harada, Y., Kobayashi, C., McCarty, W., Onogi, K., Pawson, S., Simmons, A., Wargan, K., Whitaker, J. S., and Zou, C.-Z.: Introduction to the SPARC Reanalysis Intercomparison Project (S-RIP) and overview of the reanalysis systems, Atmos. Chem. Phys., 17, 1417-1452, https://doi.org/10.5194/acp17-1417-2017, 2017.

Garcia, R. and Boville, B.: Downward control of the mean meridional circulation and temperature distribution of the polar winter stratosphere, J. Atmos. Sci., 51, 2238-2245, 1994.

Garcia, R. R., Dunkerton, T. J., Lieberman, R. S., and Vincent, R. A.: Climatology of the semi-annual oscillation of the tropical middle atmosphere, J. Geophys. Res., 102, 26019-26032, https://doi.org/10.1029/97JD00207, 1997.

Garcia, R. R., Lieberman, R. S., Russell III, J. M., and Mlynczak, M. G.: Large-scale waves in the mesosphere and lower thermosphere observed by SABER, J. Atmos. Sci., 62, 4384-4399, https://doi.org/10.1175/JAS3612.1, 2005.

Garcia, R. R., Smith, A. K., Kinnison, D. E., de la Cámara, Á., and Murphy, D. J.: Modification of the Gravity Wave Parameterization in the Whole Atmosphere Community Climate Model: Motivation and Results, J. Atmos. Sci., 74, 275-291, https://doi.org/10.1175/JAS-D-16-0104.1, 2017.

Gaspari, G. and Cohn, S. E.: Construction of correlation functions in two and three dimensions, Q. J. Roy. Meteor. Soc., 125, 723 757, https://doi.org/10.1002/qj.49712555417, 1999.

Gelaro, R., McCarty, W., Suárez, M. J., Todling, R., Molod, A., Takacs, L., Randles, C. A., Darmenov, A., Bosilovich, M. G., Reichle, R., Wargan, K., Coy, L., Cullather, R., Draper, C., Akella, S., Buchard, V., Conaty, A., da Silva, A. M., Gu, W., Kim, G.K., Koster, R., Lucchesi, R., Merkova, D., Nielsen, J. E., Partyka, G., Pawson, S., Putman, W., Rienecker, M., Schubert, S. D., Sienkiewicz, M., and Zhao, B.: The Modern-Era Retrospective Analysis for Research and Applications, Version 2 (MERRA-2), J. Climate, 30, 5419-5454, https://doi.org/10.1175/JCLI-D-160758.1, 2017.

Global Modeling and Assimilation Office (GMAO): MERRA2 inst3_3d_asm_Nv: 3d,3-Hourly, Instantaneous, ModelLevel, Assimilation, Assimilated Meteorological Fields V5.12.4, Goddard Earth Sciences Data and Information Services Center (GES DISC), Greenbelt, MD, USA, https://doi.org/10.5067/WWQSXQ8IVFW8, 2015.
Goncharenko, L. and Zhang, S.-R.: Ionospheric signatures of sudden stratospheric warming: Ion temperature at middle latitude, Geophys. Res. Lett., 35, L21103, https://doi.org/10.1029/2008GL035684, 2008.

Goncharenko, L. P., Chau, J. L., Liu, H.-L., and Coster, A. J.: Unexpected connections between the stratosphere and ionosphere, Geophys. Res. Lett., 37, L10101, https://doi.org/10.1029/2010GL043125, 2010.

Goncharenko, L. P., Coster, A. J., Plumb, R. A., and Domeisen, D. I. $\mathrm{V}$.: The potential role of stratospheric ozone in the stratosphereionosphere coupling during stratospheric warmings, Geophys Res. Lett., 39, L08101, https://doi.org/10.1029/2012GL051261, 2012.

Goncharenko, L. P., Hsu, V. W., Brum, C. G. M., Zhang, S.-R., and Fentzke, J. T.: Wave signatures in the midlatitude ionosphere during a sudden stratospheric warming of January 2010. J. Geophys. Res., 118, 472-487, https://doi.org/10.1029/2012JA018251, 2013.

Gu, S.-Y, Li, T., Dou, X., Wu, Q., Mlynczak, M. G., and Russell III, J. M.: Observations of quasi-two-day wave by TIMED/SABER and TIMED/TIDI, J. Geophys. Res.-Atmos., 118, 1624-1639, https://doi.org/10.1002/jgrd.50191, 2013.

Hagan, M. E., Maute, A., Roble, R. G., Richmond, A. D., Immel, T. J., and England, S. L.: Connections between deep tropical clouds and the Earth's ionosphere, Geophys. Res. Lett., 34, L20109, https://doi.org/10.1029/2007GL030142, 2007.

Harris, T. J.: A long-term study of the quasi-two-day wave in the middle atmosphere, J. Atmos. Terr. Phys., 56, 569-579, https://doi.org/10.1016/0021-9169(94)90098-1, 1994.

Harvey, V. L., Randall, C. E., Becker, E., Smith, A. K., Bardeen, C. G., France, J. A., and Goncharenko, L. P.: Evaluation of the mesospheric polar vortices in WACCM, J. Geophys. Res.-Atmos., 124, 10626-10645, https://doi.org/10.1020/2019JD030727, 2019.

Harvey, V. L., Knox, J. A., France, J. A., Fujiwara, M., Gray, L., Hirooka, T., Hitchcock, P., Hitchman, M., Kawatani, Y., Manney, G. L., McCormack, J., Orsolini, Y., Sakazaki, T., and Tomikawa, Y.: Chapter 11: Upper Stratosphere and Lower Mesosphere, SPARC Reanalysis Intercomparison Project (SRIP) Final Report, edited by: Fujiwara, M., Manney, G. L., Gray, L. J., and Wright, J. S., SPARC Report No. 10, WCRP-6/2021, SPARC, DLR-IPA, Oberpfaffenhofen, Germany, https://doi.org/10.17874/800dee57d13, 2021.

Hayashi, Y.: A generalized method of resolving disturbances into progressive and retrogressive waves by space Fourier and time cross-spectral analyses, J. Meteorol. Soc. Jpn., 49, 125-128, 1971.

Hindley, N. P., Wright, C. J., Hoffmann, L., Moffat-Griffin, T., and Mitchell, N. J.: An 18-year climatology of directional stratospheric gravity wave momentum flux from 3-D satellite observations, Geophys. Res. Lett., 47, e2020GL089557, https://doi.org/10.1029/2020GL089557, 2020.

Hines, C. O.: Doppler-spread parameterization of gravity-wave momentum deposition in the middle atmosphere. Part 1: Basic formulation, J. Atmos. Sol.-Terr. Phy., 59, 371-386, https://doi.org/10.1016/S1364-6826(96)00079-X, 1997.

Hoppel, K. W., Eckermann, S. D., Coy, L., Nedoluha, G. E., Allen, D. R., Swadley, S. D., and Baker, N. L.: Evaluation of SSMIS Upper Atmosphere Sounding Channels for High- 
Altitude Data Assimilation, Mon. Weather Rev., 141, 33143330, https://doi.org/10.1175/MWR-D-13-00003.1, 2013.

Immel, T. J., Sagawa, E., England, S. L., Henderson, S. B., Hagan, M. E., Mende, S. B., Frey, H. U., Swenson, C. M., and Paxton, L. J.: Control of equatorial ionospheric morphology by atmospheric tides, Geophys. Res. Lett., 33, L15108, https://doi.org/10.1029/2006GL026161, 2006.

Jones Jr., M., Drob, D. P., Siskind, D. E., McCormack, J. P., Maute, A., McDonald, S. E., and Dymond, K. F.: Evaluating different techniques for constraining lower atmospheric variability in an upper atmosphere general circulation model: A case study during the 2010 sudden stratospheric warming, J. Adv. Model. Earth Sy., 10, 3076-3102. https://doi.org/10.1029/2018MS001440, 2018.

Kalnay, E., Kanamitsu, M., Kistler, R., Collins, W., Deaven, D., Gandin, L., Iredell, M., Saha, S., White, G., Woollen, J., Zhu, Y., Chelliah, M., Ebisuzaki, W., Higgins, W., Janowiak, J., Mo, K. C. Ropelewski, C., Wang, J., Leetmaa, A., Reynolds, R., Jenne, R., and Joseph, D.: The NCEP/NCAR 40-year reanalysis project, B. Am. Meteorol. Soc., 77, 437-472, https://doi.org/10.1175/15200477(1996)077<0437:TNYRP>2.0.CO;2, 1996.

Karlsson, B. and Becker, E.: How Does Interhemispheric Coupling Contribute to Cool Down the Summer Polar Mesosphere?, J. Climate, 29, 8807-8821, 2016.

Karlsson, B., McLandress, C., and Shepherd, T. G.: Interhemispheric mesospheric coupling in a comprehensive middle atmosphere model, J. Atmos. Sol.-Terr. Phy., 71, 518-530, https://doi.org/10.1016/j.jastp.2008.08.006, 2009a.

Karlsson, B., Randall, C. E., Benze, S., Mills, M., Harvey, V. L., Bailey, S., M., and Russell III, J. M.: Intraseasonal variability of polar mesospheric clouds due to inter-hemispheric coupling. Geophys. Res. Lett., 36, L20802, https://doi.org/10.1029/2009GL040348, 2009b.

Kawatani, Y., Hamilton, K., Miyazaki, K., Fujiwara, M., and Anstey, J. A.: Representation of the tropical stratospheric zonal wind in global atmospheric reanalyses, Atmos. Chem. Phys., 16, 6681-6699, https://doi.org/10.5194/acp-16-6681-2016, 2016.

Kawatani, Y., Hirooka, T., Hamilton, K., Smith, A. K., and Fujiwara, M.: Representation of the equatorial stratopause semiannual oscillation in global atmospheric reanalyses, Atmos. Chem. Phys., 20, 9115-9133, https://doi.org/10.5194/acp-209115-2020, 2020.

Kistler, R., Kalnay, E., Collins, W., Saha, S., White, G., Woollen, J., Chelliah, M., Ebisuzaki, W., Kanamitsu, M., Kousky, V., van den Dool, H., Jenne, R., and Fiorino, M.: The NCEP-NCAR 50year reanalysis: monthly means CD-ROM and documentation, B. Am. Meteorol. Soc., 82, 247-267, https://doi.org/10.1175/15200477(2001)082<0247:TNNYRM>2.3.CO;2, 2001.

Kobayashi, S., Ota, Y., Harada, Y., Ebita, A., Moriya, M., Onoda, H., Onogi, K., Kamahori, H., Kobayashi, C., Endo, H., Miyaoka, K., and Takahashi, K.: The JRA-55 reanalysis: general specifications and basic characteristics, J. Meteorol. Soc. Jpn., 93, 5-48, https://doi.org/10.2151/jmsj.2015-001, 2015.

Koshin, D., Sato, K., Miyazaki, K., and Watanabe, S.: An ensemble Kalman filter data assimilation system for the whole neutral atmosphere, Geosci. Model Dev., 13, 3145-3177, https://doi.org/10.5194/gmd-13-3145-2020, 2020.

Koshin, D., Sato, K., Kohma, M., and Watanabe, S.: An update on the 4D-LETKF data assimilation system for the whole neutral atmosphere, Geosci. Model Dev. Discuss. [preprint], https://doi.org/10.5194/gmd-2020-381, in review, 2021.

Koushik, N., Kumar, K. K., Ramkumar, G., Subrahmanyam, K. V., Kishore Kumar, G., Hocking, W. K., He, M., and Latteck, R.: Planetary waves in the mesosphere lower thermosphere during stratospheric sudden warming: observations using a network of meteor radars from high to equatorial latitudes, Clim. Dynam. 54, 4059-4074, https://doi.org/10.1007/s00382020-05214-5, 2020.

Kuhl, D. D., Rosmond, T. E., Bishop, C. H., McLay, J., and Baker, N. L.: Comparison of Hybrid Ensemble/4DVar and 4DVar within the NAVDAS-AR Data Assimilation Framework, Mon. Weather Rev., 141, 2740-2758, 2013.

umar, K. K., Subrahmanyam, K. V., Mathew, S. S., Koushik, N., and Ramkumar, G.: Simultaneous observations of the quasi 2day wave climatology over the low and equatorial latitudes in the mesosphere lower thermosphere, Clim. Dynam, 51, 221-233, https://doi.org/10.1007/s00382-017-3916-2, 2018.

Labitzke, K.: Temperature changes in the mesosphere and stratosphere connected with circulation changes in winter, J. Atmos. Sci., 29, 756-766, https://doi.org/10.1175/15200469(1972)029<0756:TCITMA>2.0.CO;2, 1972.

Laskar, F. I., McCormack, J. P., Chau, J. L., Pallamraju, D., Hoffmann, P., and Singh, R. P.: Interhemispheric meridional circulation during sudden stratospheric warming, J. Geophys. Res., 124, 7112-7122, https://doi.org/10.1029/2018JA026424, 2019.

Lewis, H.: Geodesy calculations in ROPP, GRAS SAF Report 02, Met Office, Exeter, United Kingdom, 2007.

Lieberman, R. S., Riggin, D. M. Franke, S. J. Manson, A. H. Meek, C. Nakamura, T. Tsuda, T. Vincent, R. A., and Reid, I.: The 6.5day wave in the mesosphere and lower thermosphere: Evidence for baroclinic/barotropic instability, J. Geophys. Res., 108, 4640, https://doi.org/10.1029/2002JD003349, 2003.

Lieberman, R. S., Riggin, D. M., Ortland, D. A., Oberheide, J., and Siskind, D. E.: Global observations and modeling of nonmigrating diurnal tides generated by tide-planetary wave interactions, J. Geophys. Res.-Atmos., 120, 11419-11437, https://doi.org/10.1002/2015JD023739, 2015.

Lieberman, R. S., France, J., Ortland, D. A., and Eckermann, S. D.: The role of inertial instability in cross-hemispheric coupling, J. Atmos. Sci., 78, 1113-1127, https://doi.org/10.1175/JAS-D-200119.1, 2021.

Lilienthal, F. and Jacobi, Ch.: Meteor radar quasi 2-day wave observations over 10 years at Collm $\left(51.3^{\circ} \mathrm{N}, 13.0^{\circ} \mathrm{E}\right)$, Atmos. Chem. Phys., 15, 9917-9927, https://doi.org/10.5194/acp15-9917-2015, 2015.

Lima, L. M., Alves, E. O., Batista, P. P., Clemesha, B. R., Medeiros, A. F., and Buriti, R. A.: Sudden stratospheric warming effects on the mesospheric tides and 2-day wave dynamics at $7^{\circ} \mathrm{S}$, J. Atmos. Sol.-Terr. Phys., 78-79, 99-107, https://doi.org/10.1016/j.jastp.2011.02.013, 2012.

Limpasuvan, V. and Wu, D. L.: Two-day wave observations of UARS Microwave Limb Sounder mesospheric water vapor and temperature, J. Geophys. Res., 108, 4307, https://doi.org/10.1029/2002JD002903, 2003.

Limpasuvan, V., Orsolini, Y. J., Chandran, A., Garcia, R. R., and Smith, A. K.: On the composite response of the MLT to major sudden stratospheric warming events with ele- 
vated stratopause, J. Geophys. Res.-Atmos., 121, 4518-4537, https://doi.org/10.1002/2015JD024401, 2016.

Liu, H.-L., Bardeen, C. G., Foster, B. T., Lauritzen, P., Liu, J., Lu, G., Marsh, D. R., Maute, A., McInerney, J. M., Pedatella, N. M., Qian, L., Richmond, A. D., Roble, R. G., Solomon, S. C., Vitt, F. M., and Wang, W.: Development and validation of the Whole Atmosphere Community Climate Model with thermosphere and ionosphere extension, J. Adv. Model. Earth Sy., 10, 381-402. https://doi.org/10.1002/2017MS001232, 2018.

Manney, G. L., Krüger, K., Pawson, S., Minschwaner, K., Schwartz, M. J., Daffer, W. H., Livesey, N. J., Mlynczak, M. G., Remsberg, E. E., Russell III, J. M., and Waters, J .W.: The evolution of the stratopause during the 2006 major warming: Satellite data and assimilated meteorological analyses, J. Geophys. Res., 113, D11115, https://doi.org/10.1029/2007JD009097, 2008.

Marlton, G., Charlton-Perez, A., Harrison, G., Polichtchouk, I., Hauchecorne, A., Keckhut, P., Wing, R., Leblanc, T., and Steinbrecht, W.: Using a network of temperature lidars to identify temperature biases in the upper stratosphere in ECMWF reanalyses, Atmos. Chem. Phys., 21, 6079-6092, https://doi.org/10.5194/acp-21-6079-2021, 2021.

Marsh, D. R., Mills, M. J., Kinnison, D. E., Lamarque, J. F., Calvo, N., and Polvani, L. M.: Climate change from 1850 to 2005 simulated in CESM1 (WACCM), J. Climate, 26, 7372-7391, https://doi.org/10.1175/JCLI-D-12-00558.1, 2013.

Matsuno, T.: A Dynamical Model of the Stratospheric Sudden Warming, J. Atmos. Sci., 28, 1479-1494, https://doi.org/10.1175/15200469(1971)028<1479:ADMOTS>2.0.CO;2, 1971.

Maute, A., Hagan, M. E., Richmond, A. D., and Roble, R. G.: TIME-GCM study of the ionospheric equatorial vertical drift changes during the 2006 stratospheric sudden warming, J. Geophys. Res.-Space, 119, 1287-1305, https://doi.org/10.1002/2013JA019490, 2014.

McCarty, W., Coy, L., Gelaro, R., Huang, A., Merkova, D., Smith, E. B., Seinkiewicz, M., and Wargan, K.: MERRA-2 Input Observations: Summary and Assessment, NASA Technical Report Series on Global Modeling and Data Assimilation, NASA/TM2016-104606, vol. 46, NASA Goddard Space Flight Center, Greenbelt, Maryland, 2016.

McCormack, J. P., Coy, L., and Hoppel, K. W.: Evolution of the quasi 2-day wave during January 2006, J. Geophys. Res., 114, D20115, https://doi.org/10.1029/2009JD012239, 2009.

McCormack, J. P., Coy, L., and Singer, W.: Intraseasonal and interannual variability of the quasi 2-day wave in the Northern Hemisphere summer mesosphere, J. Geophys. Res.-Atmos., 119, 2928-2946, https://doi.org/10.1002/2013JD020199, 2014.

McCormack, J., Hoppel, K., Kuhl, D., de Wit, R., Stober, G., Espy, P., Baker, N., Brown, P., Fritts, D., Jacobi, C., Janches, D., Mitchell, N., Ruston, B., Swadley, S., Viner, K., Whitcomb, T., and Hibbins, R.: Comparison of mesospheric winds from a high-altitude meteorological analysis system and meteor radar observations during the boreal winters of 20092010 and 2012-2013, J. Atmos. Sol.-Terr. Phy., 154, 132-166, https://doi.org/10.1016/j.jastp.2016.12.007, 2017.

McCormack, J., Harvey, V. L., Randall, C., Pedatella, N., Koshin, D., Sato, K., Coy, L., Watanabe, S., Sassi, F., and Holt, L.: Intercomparison of Middle Atmospheric Meteorological Analyses for the Northern Hemisphere Winter 2009-2010, Zenodo [data set], https://doi.org/10.5281/zenodo.5567401, 2021.

McDonald, S. E., Sassi, F., Tate, J., McCormack, J., Kuhl, D. D., Drob, D. P., Metzler, C., and Mannucci, A. J.: Impact of nonmigrating tides on the low latitude ionosphere during a sudden stratospheric warming event in January 2010, J. Atmos. Sol.-Terr. Phy., 171, 188-200, https://doi.org/10.1016/j.jastp.2017.09.012, 2018.

McFarlane, N. A.: The Effect of Orographically Excited Gravity Wave Drag on the General Circulation of the Lower Stratosphere and Troposphere, J. Atmos. Sci., 44, 1775-1800, https://doi.org/10.1175/15200469(1987)044<1775:TEOOEG>2.0.CO;2, 1987.

McLandress, C.: Interannual variations of the diurnal tide in the mesosphere induced by a zonal-mean wind oscillation in the tropics, Geophys. Res. Lett., 29, 1305, https://doi.org/10.1029/2001GL014551, 2002.

Miyoshi, Y. and Hirooka, T.: Quasi-biennial variation of the 5day wave in the stratosphere, J. Geophys. Res., 108, 4620, https://doi.org/10.1029/2002JD003145, 2003.

Miyoshi, T. and Yamane, S.: Local ensemble transform Kalman filtering with an AGCM at a T159/L48 resolution. Mon. Weather Rev., 135, 3841-3861, https://doi.org/10.1175/2007MWR1873.1, 2007.

Molod, A., Takacs, L., Suarez, M., and Bacmeister, J.: Development of the GEOS-5 atmospheric general circulation model: evolution from MERRA to MERRA2, Geosci. Model Dev., 8, 1339-1356, https://doi.org/10.5194/gmd-8-1339-2015, 2015.

Neale, R. B., Richter, J. H., Park, S., Lauritzen, P. H., Vavrus, S. J., Rasch, P. J., and Zhang, M.: The mean climate of the Community Atmosphere Model (CAM4) in forced SST and fully coupled experiments, J. Climate, 26, 5150-5168, https://doi.org/10.1175/JCLI-D-12-00236.1, 2013.

Orsolini, Y. J., Limpasuvan, V., and Leovy, C. B.: The tropical stratopause response in the UKMO stratospheric analyses: Evidence for a 2-day wave and inertial circulations, Q. J. Roy. Meteor. Soc., 123, 1707-1724, https://doi.org/10.1002/qj.49712354212, 1997.

Pancheva, D. V.: Quasi-2-day wave and tidal variability observed over Ascension Island during January/February 2003, J. Atmos. Terr. Phys., 68, 390-407, https://doi.org/10.1016/j.jastp.2005.02.028, 2006.

Pedatella, N.: WACCMX DART 2010 Northern Hemisphere Winter Temperature and Wind. Version 1.0, UCAR/NCAR - DASH Repository [data set], https://doi.org/10.5065/d88c-y005, 2021.

Pedatella, N. M. and Forbes, J. M.: Evidence for stratosphere sudden warming-ionosphere coupling due to vertically propagating tides, Geophys. Res. Lett., 37, L11104, https://doi.org/10.1029/2010GL043560, 2010.

Pedatella, N. M. and Liu, H.-L.: The influence of atmospheric tide and planetary wave variability during sudden stratosphere warmings on the low latitude ionosphere, J. Geophys. Res.-Space, 118, 5333-5347, https://doi.org/10.1002/jgra.50492, 2013.

Pedatella, N. M., Fuller-Rowell, T., Wang, H., Jin, H., Miyoshi, Y., Fujiwara, H., Shinagawa, H., Liu, H.-L., Sassi, F., Schmidt, H., Matthias, V., and Goncharenko, L.: The neutral dynamics during the 2009 sudden stratosphere warming simulated by different whole atmosphere models, J. Geophys. Res.-Space, 119, 13061324, https://doi.org/10.1002/2013JA019421, 2014a. 
Pedatella, N. M., Raeder, K., Anderson, J. L., and Liu, H.-L.: Ensemble data assimilation in the Whole Atmosphere Community Climate Model, J. Geophys. Res.-Atmos., 119, 9793-9809, https://doi.org/10.1002/2014JD021776, 2014b.

Pedatella, N. M., Liu, H.-L., Marsh, D. R., Raeder, K., Anderson, J. L., Chau, J. L., Goncharenko, L. P., and Siddiqui, T. A.: Analysis and hindcast experiments of the 2009 sudden stratospheric warming in WACCMX+DART, J. Geophys. Res.-Space, 123, 3131-3153, https://doi.org/10.1002/2017JA025107, 2018.

Pedatella, N. M., Liu, H.-L., Marsh, D. R., Raeder, K., and Anderson, J. L.: Error growth in the mesosphere and lower thermosphere based on hindcast experiments in a whole atmosphere model, Space Weather, 17, 1442-1460, https://doi.org/10.1029/2019SW002221, 2019.

Pedatella, N. M., Anderson, L., Chen, C. H., Raeder, K., Liu, J., Liu, H.-L., and Lin, C. H.: Assimilation of ionosphere observations in the Whole Atmosphere Community Climate Model with thermosphere-ionosphere eXtension (WACCMX), J. Geophys. Res., 125, e2020JA028251, https://doi.org/10.1029/2020JA028251, 2020.

Pfister, L.: Baroclinic instability of easterly jets with applications to the summer mesosphere, J. Atmos. Sci., 42, 313-330, https://doi.org/10.1175/15200469(1985)042<0313:BIOEJW>2.0.CO;2, 1985.

Plumb, R. A.: Baroclinic instability of the summer mesosphere: A mechanism for the quasi-two-day wave?, J. Atmos. Sci., 40, 262-270, https://doi.org/10.1175/15200469(1983)040<0262:BIOTSM>2.0.CO;2, 1983.

Remsberg, E. E., Marshall, B. T., Garcia-Comas, M., Krueger, D., Lingenfelser, G. S., Martin-Torres, J., Mlynczak, M. G., Russell III, J. M., Smith, A. K., Zhao, Y., Brown, C., Gordley, L. L., Lopez-Gonzalez, M. J., Lopez-Puertas, M., She, C.-Y., Taylor, M. J., and Thompson, R. E.: Assessment of the quality of the Version 1.07 temperature-versus-pressure profiles of the middle atmosphere from TIMED/SABER, J. Geophys. Res., 113, D17101, https://doi.org/10.1029/2008JD010013, 2008.

Richter, J. H., Sassi, F., and Garcia, R. R.: Towards a physically based gravity wave source parameterization in a general circulation model, J. Atmos. Sci., 67, 136-156, https://doi.org/10.1175/2009JAS3112.1, 2010.

Sakazaki, T., Fujiwara, M., Zhang, X., Hagan, M. E., and Forbes, J. M.: Diurnal tides from the troposphere to the lower mesosphere as deduced from TIMED/SABER satellite data and six global reanalysis data sets, J. Geophys. Res., 117, D13108, https://doi.org/10.1029/2011JD017117, 2012.

Salby, M. L.: Rossby normal modes in nonuniform background configurations. Part II. Equinox and solstice conditions, J. Atmos. Sci., 38, 9, 1827-1840, https://doi.org/10.1175/15200469(1981)038<1827:RNMINB>2.0.CO;2, 1981.

Sassi, F. and Liu, H.-L.: Westward traveling planetary wave events in the lower thermosphere during solar minimum conditions simulated by SD-WACCM-X, J. Atmos. Sol. Terr. Phy., 119, 11-26, https://doi.org/10.1016/j.jastp.2014.06.009, 2014.

Sassi, F., Garcia, R. R., and Hoppel, K. W.: Large-scale Rossby normal modes during some recent northern hemisphere winters, J. Atmos. Sci., 69, 820-839, https://doi.org/10.1175/JAS-D-110103.1, 2012.

Sassi, F., Liu, H.-L., Ma, J., and Garcia, R. R.: The lower thermosphere during the northern hemisphere winter of 2009:
A modeling study using high-altitude data assimilation products in WACCM-X, J. Geophys. Res.-Atmos., 118, 8954-8968, https://doi.org/10.1002/jgrd.50632, 2013.

Sassi, F., Liu, H.-L., and Emmert, J. T.: Traveling planetary-scale waves in the lower thermosphere: Effects on neutral density and composition during solar minimum conditions, J. Geophys. Res.Space, 121, 1780-1801, https://doi.org/10.1002/2015JA022082, 2016.

Sassi, F., Siskind, D. E., Tate, J. L., Liu, H.-L., and Randall, C. E.: Simulations of the boreal winter upper mesosphere and lower thermosphere with meteorological specifications in SD-WACCM-X, J. Geophys. Res., 123, 3791-3811, https://doi.org/10.1002/2017JD027782, 2018.

Sassi, F., McCormack, J. P., and McDonald, S. E.: Whole atmosphere coupling on intraseasonal and interseasonal time scales: A potential source of increased predictive capability, Radio Sci., 54, 913-933, https://doi.org/10.1029/2019RS006847, 2019.

Sassi, F., McCormack, J. P., Tate, J. L., Kuhl, D. D., and Baker, N. L.: Assessing the impact of middle atmosphere observations on day-to-day variability in lower thermospheric winds using WACCM-X, J. Atmos. Sol.-Terr. Phy., 212, 105486, https://doi.org/10.1016/j.jastp.2020.105486, 2021.

Sato, K., Yasui, R., and Miyoshi, Y.: The Momentum Budget in the Stratosphere, Mesosphere, and Lower Thermosphere. Part I: Contributions of Different Wave Types and In Situ Generation of Rossby Waves, J. Atmos. Sci., 75, 3613-3633, https://doi.org/10.1175/JAS-D-17-0336.1, 2018.

Schoeberl, M. R., Douglass, A. R., Hilsenrath, E., Bhartia, P. K., Beer, R., Waters, J. W., Gunson, M. R., Froidevaux, L., Gille, J. C., Barnett, J. J., Levelt, P. F., and DeCola, P.: Overview of the EOS Aura Mission, IEEE T. Geosci. Remote, 44, 1066-1074, https://doi.org/10.1109/TGRS.2005.861950, 2006.

Schwartz, M. J., Lambert, A., Manney, G. L., Read, W. G., Livesey, N. J., Froidevaux, L., Ao, C. O., Bernath, P. F., Boone, C. D., Cofield, R. E., Daffer, W. H., Drouin, B. J., Fetzer, E. J., Fuller, R. A., Jarnot, R. F., Jiang, J. H., Jiang, Y. B., Knosp, B. W., Krüger, K., Li, J.-L. F., Mlynczak, M. G., Pawson, S., Russell III, J. M., Santee, M. L., Snyder, W. V., Stek, P. C., Thurstans, R. P., Tompkins, A. M., Wagner, P. A., Walker, K. A., Waters, J. W., and Wu, D. L.: Validation of the Aura Microwave Limb Sounder temperature and geopotential height measurements, J. Geophys. Res., 113, D15S11, https://doi.org/10.1029/2007JD008783, 2008.

Siddiqui, T. A., Maute, A., and Pedatella, N. M.: On the Importance of Interactive Ozone Chemistry in Earth-System Models for Studying Mesophere-Lower Thermosphere Tidal Changes during Sudden Stratospheric Warmings, J. Geophys. Res.-Space, 124, 10690-10707, https://doi.org/10.1029/2019JA027193, 2019.

Siskind, D. E. and McCormack, J. P.: Summer mesospheric warmings and the quasi-2 day wave, Geophys. Res. Lett., 41, 717-722, https://doi.org/10.1002/2013GL058875, 2014.

Siskind, D. E., Eckermann, S. D., McCormack, J. P., Coy, L., Hoppel, K. W., and Baker, N. L.: Case studies of the mesospheric response to recent minor, major, and extended stratospheric warmings, J. Geophys. Res., 115, D00N03, https://doi.org/10.1029/2010JD014114, 2010.

Siskind, D. E., Jones Jr., M., Drob, D. P., McCormack, J. P., Hervig, M. E., Marsh, D. R., Mlynczak, M. G., Bailey, S. M., Maute, A., and Mitchell, N. J.: On the relative roles of dynamics and 
chemistry governing the abundance and diurnal variation of lowlatitude thermospheric nitric oxide, Ann. Geophys., 37, 37-48, https://doi.org/10.5194/angeo-37-37-2019, 2019.

Smith, A. K.: The origin of stationary planetary waves in the upper mesosphere, J. Atmos. Sci., 60, 3033-3041, 2003.

Smith, A. K.: Global dynamics of the MLT, Surv. Geophys., 33, 1177-1230, https://doi.org/10.1007/s10712-012-9196-9, 2012.

Smith, A. K., Pedatella, N. M., and Mullen, Z. K.: Interhemispheric coupling mechanisms in the middle atmosphere of WACCM6, J. Atmos. Sci., 77, 1101-1118, https://doi.org/10.1175/JAS-D-190253.1, 2020.

Stober, G., Baumgarten, K., McCormack, J. P., Brown, P., and Czarnecki, J.: Comparative study between ground-based observations and NAVGEM-HA analysis data in the mesosphere and lower thermosphere region, Atmos. Chem. Phys., 20, 11979-12010, https://doi.org/10.5194/acp-20-11979-2020, 2020.

Stockwell, R. G., Mansinha, L., and Lowe, R. P.: Localization of the complex spectrum: The $\mathrm{S}$ transform, IEEE T. Signal Proces., 44, 998-1001, 1996.

Stray, N. H., Orsolini, Y. J., Espy, P. J., Limpasuvan, V., and Hibbins, R. E.: Observations of planetary waves in the mesospherelower thermosphere during stratospheric warming events, Atmos. Chem. Phys., 15, 4997-5005, https://doi.org/10.5194/acp15-4997-2015, 2015.

Talaat, E. R., Yee, J.-H., and Zhu, X.: Observations of the 6.5-day wave in the mesosphere and lower thermosphere, J. Geophys. Res., 106, 20715-20723, https://doi.org/10.1029/2001JD900227, 2001.

Torrence, C. and Compo, G. P.: A Practical Guide to Wavelet Analysis, B. Am. Meteorol. Soc., 79, 61-78, https://doi.org/10.1175/15200477(1998)079\%3C0061:APGTWA\%3E2.0.CO;2, 1998.

Tunbridge, V. M., Sandford, D. J., and Mitchell, N. J.: Zonal wave numbers of the summertime 2-day planetary wave observed in the mesosphere by EOS Aura Microwave Limb Sounder, J. Geophys. Res., 116, D11103, https://doi.org/10.1029/2010JD014567, 2011.

Tweedy, O. V., Limpasuvan, V., Orsolini, Y. J., Smith, A. K., Garcia, R. R., Kinnison, D., Randall, C. E., Kvissel, O.-K., Stordal, F., Harvey, V. L., and Chandran, A.: Nighttime secondary ozone layer during major stratospheric sudden warmings in specified-dynamics WACCM, J. Geophys. Res., 118, 83468358, https://doi.org/10.1002/jgrd.50651, 2013.
Vadas, S. L. and Becker, E.: Numerical modeling of the excitation, propagation, and dissipation of primary and secondary gravity waves during wintertime at McMurdo Station in the Antarctic, J. Geophys. Res., 123, 9326-9369, https://doi.org/10.1029/2017JD027974, 2018.

Watanabe, S.: Constraints on a Non-orographic Gravity Wave Drag Parameterization Using a Gravity Wave Resolving General Circulation Model, SOLA, 4, 61-64, https://doi.org/10.2151/sola.2008-016, 2008.

Watanabe, S. and Miyahara, S.: Quantification of the gravity wave forcing of the migrating diurnal tide in a gravity wave-resolving general circulation model, J. Geophys. Res., 114, D07110, https://doi.org/10.1029/2008JD011218, 2009.

Webster, S., Brown, A. R., Cameron, D. R., and Jones, C. P.: Improvements to the representation of orography in the Met Office Unified Model, Q. J. Roy. Meteor. Soc., 129, 1989-2010, https://doi.org/10.1256/qj.02.133, 2003.

Yee, J.-H., Cameron, G. E., and Kusnierkiewicz, D. Y.: Overview of TIMED, Proc. SPIE 3756, Optical Spectroscopic Techniques and Instrumentation for Atmospheric and Space Research III, Denver, Colorado, United States, https://doi.org/10.1117/12.366378, 1999.

Yue, J., Wang, W., Richmond, A. D., and Liu, H.-L.: Quasitwo-day wave coupling of the mesosphere and lower thermosphere-ionosphere in the TIME-GCM: Two-day oscillations in the ionosphere, J. Geophys. Res., 117, A07305, https://doi.org/10.1029/2012JA017815, 2012.

Zhang, X., Forbes, J. M., Hagan, M. E., Russell III, J. M., Palo, S. E., Mertens, C. J., and Mlynczak, M. G.: Monthly tidal temperatures 20-120 km from TIMED/SABER, J. Geophys. Res., 111, A10S08, https://doi.org/10.1029/2005JA011504, 2006.

Zülicke, C., Becker, E., Matthias, V., Peters, D. H. W., Schmidt, H., Liu, H.-L., de la Torre Ramos, L., and Mitchell, D.M.: Coupling of Stratospheric Warmings with Mesospheric Coolings in Observations and Simulations, J. Climate, 31, 1107-1133, https://doi.org/10.1175/JCLI-D-17-0047.1, 2018. 